\title{
La villa de Rufio (Giano dell'Umbria, PG-Italia): fases constructivas y desarrollo de un modelo productivo esclavista*
}

\section{The Villa of Rufio (Giano dell'Umbria, PG-Italy): building stages and development of a slave production model}

\author{
Jaime Molina Vidal \\ Universidad de Alicante \\ jaime.molina@ua.es \\ ORCID iD: https://orcid.org/0000-0001-5481-2811 \\ María Juana López Medina \\ Universidad de Almería \\ jlmedina@ual.es \\ ORCID iD: https://orcid.org/0000-0003-3123-3969
}

Enviado: 18-12-2019. Aceptado: 21-06-2020. Publicado online: 02-06-2021

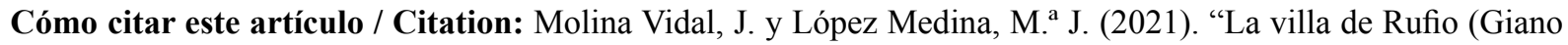
dell'Umbria, PG-Italia): fases constructivas y desarrollo de un modelo productivo esclavista". Archivo Español de Arqueología, 94, e08. DOI: https://doi.org/10.3989/aespa.094.021.08

RESUMEN: Se presenta la villa romana de Gaius Iulius Rufio, situada en la via Flaminia (Regio VI, Italia) y su evolución cronológica. El análisis de las fases del conjunto arquitectónico se basa en el estudio de los mosaicos y las curvas cronológicas realizadas a partir de la cuantificación cerámica. La villa fue construida en el último cuarto del siglo I a. C. como villa esclavista, presentando un ergastulum en la pars rustica (Fase 1). En la segunda mitad del siglo I d. C. se observa una fuerte remodelación del conjunto (Fase 2) con la amortización del ergastulum y la extensión de estructuras productivas en la pars urbana. Esta fase marcaría un límite máximo de extensión de los sistemas esclavistas en esta región que podría servir de referencia para el conjunto villas esclavistas romanas en Italia. A finales del siglo I d. C. o principios del siglo II d. C. el conjunto presenta potentes fases de destrucción y abandono.

Palabras clave: esclavitud; siglo I; Augusto; ergastulum; cuantificación; mosaicos; via Flaminia; Gaius Iulius.

\footnotetext{
* Agradecemos el trabajo conjunto y amistad de S. Creatore, G. Terenzi, I. Pennacchi, M. Giovannelli, F. Schippa y B. Iacobazzi, así como el apoyo de la EEHAR-CSIC, del entonces director R. Olmos Romera. La investigación fue financiada por el Ministerio de Cultura (IPHE/ PERUSA07-11) y la Universidad de Alicante (ACIE2008-2013 y HAR2009-09104). Dedicamos este trabajo a uno de sus impulsores iniciales el prof. M. Carrilero Millán (Univ. Almería).
} 
ABSTRACT: In this paper we present the Roman villa of Gaius Iulius Rufio, located on the via Flaminia (Regio VI, Italy) and its chronological evolution. The analysis of the phases of the architectural complex is based on the study of mosaics and chronological trend established by from pottery quantification. The villa was built in the last quarter of the $1^{\text {st }}$ century BC as a slave estate, presenting an ergastulum in the pars rustica (phase 1). In the second half of the $1^{\text {st }}$ century AD there was a strong rebuilding of the complex (phase 2) with the amortization of the ergastulum and the extension of productive structures in the pars urbana. This phase would mark a maximum limit of extension of the slavery systems in this region, that could serve as a reference for all the roman slavery villae in Italy. At the end of the $1^{\text {st }} \mathrm{AD}$ or early $2^{\text {nd }} \mathrm{AD}$ the site presents a clear context of destruction and abandonment.

Keywords: slavery; $1^{\text {st }}$ century AD; Augustus; ergastulum; quantification; mosaics; via Flaminia; Gaius Iulius.

Copyright: (C) 2021 CSIC. Este es un artículo de acceso abierto distribuido bajo los términos de la licencia de uso y distribución Creative Commons Reconocimiento 4.0 Internacional (CC BY 4.0).

\section{INTRODUCCIÓN}

La villa de Rufio se halla al sur de la región de Umbría (Italia) (Regio VI), en el municipio de Giano dell’Umbria. Se situaba en la antigua vía Flaminia, entre la Mansio Ad Martis (Massa Martana) y Mevania (Bevagna), a 1,5 km del cruce con la antigua vía Tuderte, y con un posible acceso fluvial en Tuder (Todi) a $15 \mathrm{~km}$ u Ocriculum (Otricoli) a 50 km (Fig. 1).

El yacimiento fue descubierto en el año 2002 por la Società Cooperativa Kronos que desarrolló su excavación de forma autónoma hasta el año 2006. Por expresa invitación de la Soprintendenza per $i$ Beni Archeologici dell'Umbria y el Comune di Giano dell'Umbria, y de forma coordinada con los directores de las excavaciones, el año 2008 un equipo de la
Universidad de Alicante dirigido por J. Molina Vidal asumió la codirección de la excavación de la villa que se desarrolló hasta el año 2013. Habría que destacar que la excavación del conjunto arqueológico ha contado con la oposición de algunos propietarios de las parcelas del Área 2 de la villa (pars fructuaria y urbana), en cualquier caso, muy arrasadas por las labores agrícolas. Todo ello ha impedido continuar las investigaciones de campo y desarrollar el programa completo de excavaciones en la pars fructuaria ( $c$. $775 \mathrm{~m}^{2}$ ) situada al norte y noroeste de esta (Fig. 2), en la que hemos documentado múltiples restos de balsas pavimentadas con mortero hidráulico y opus spicatum. Mientras que en la pars urbana (Área 2), solo se han podido desarrollar dos campañas de excavación muy superficiales y fragmentarias. Así pues, solo se
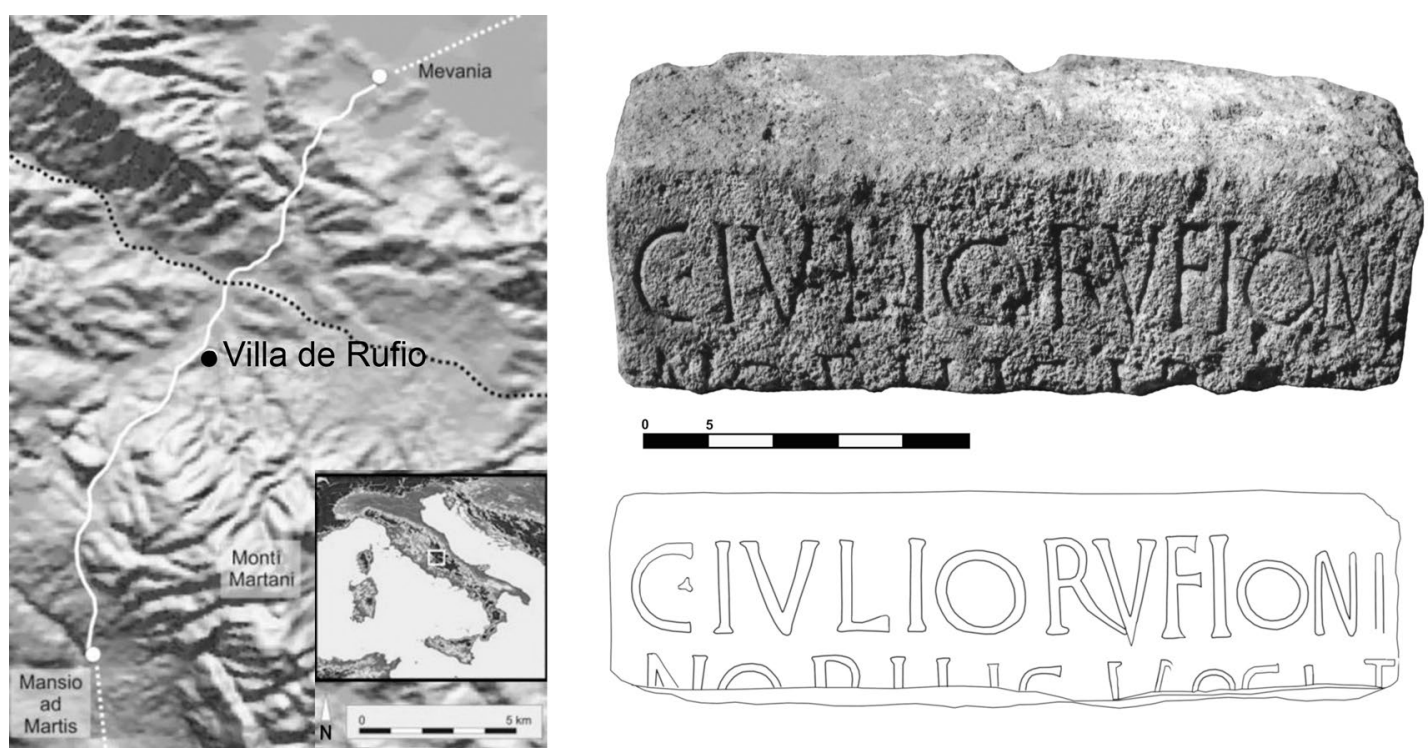

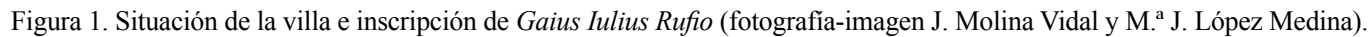


ha podido concluir la excavación del Área 1 (pars rustica), que ofreció buenos niveles estratigráficos para analizar y datar la fase de abandono, pero no los constructivos, muy arrasados y sin apenas material con valor cronológico. Todo ello justifica que, para datar las fases constructivas, más que elementos de carácter estrictamente estratigráficos hayamos de recurrir principalmente a la datación ofrecida por los pavimentos de mosaico de opus tesellatum.

En este trabajo no vamos a analizar de forma preferente el ergastulum de la villa y su carácter esclavista, extremos ya demostrados en otros ámbitos (Molina et al., 2017), sino que señalaremos el marco cronológico de su desarrollo a través de sus fases constructivas, lo que ofrecerá nuevos parámetros para enmarcar la extensión de la producción esclavista en la propia Italia. No pretendemos decir con esto que la villa de Rufio deba ser el único elemento para determinar el declive de la producción esclavista en Italia. Sin embargo, dado que la villa de Rufio contiene uno de los más claros ejemplos de ergastulum del Imperio romano, como hemos destacado en publicaciones anteriores (Molina et al., 2017), su ubicación cronológica, objeto preferente de este artículo, será un elemento de obli-

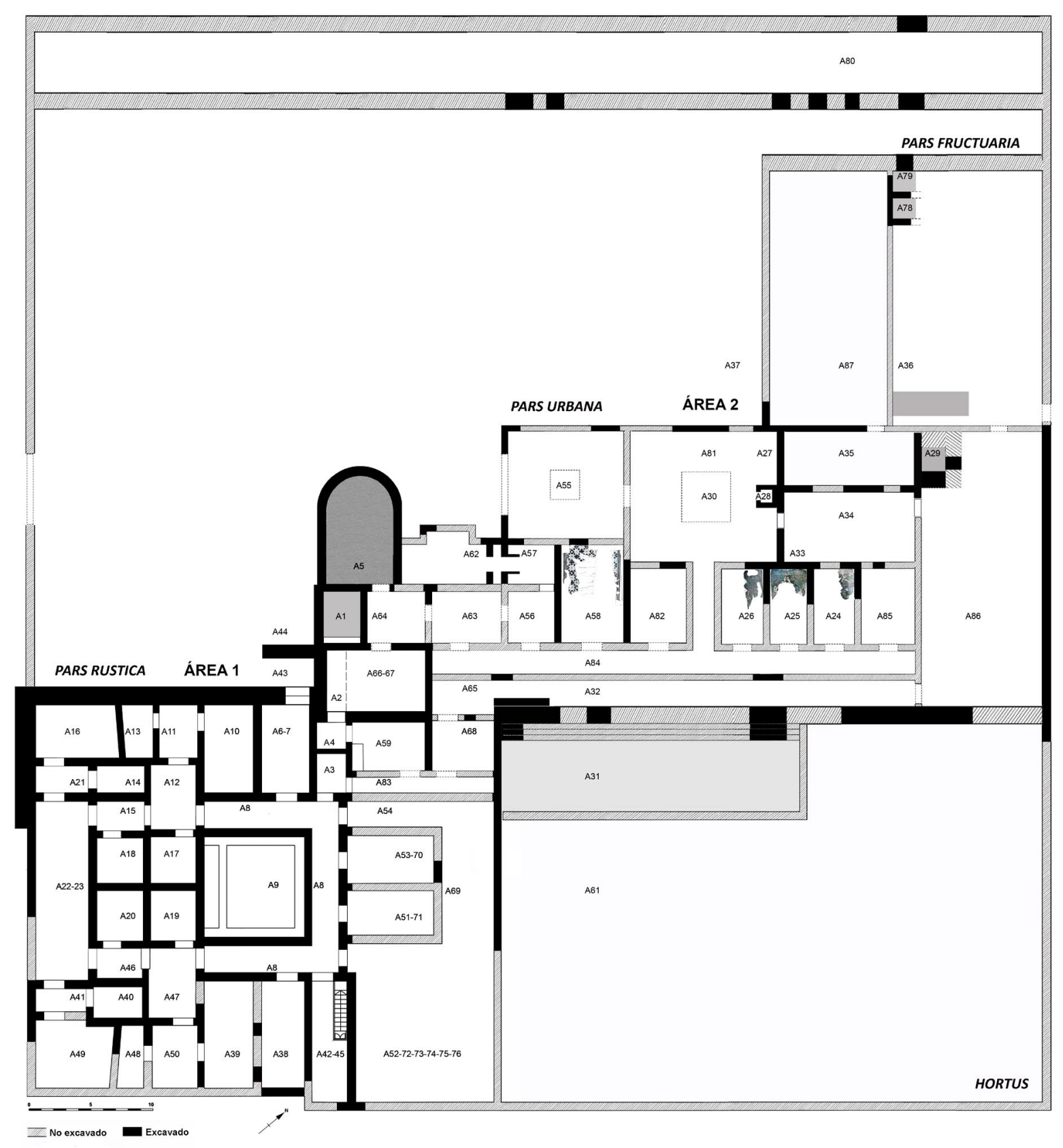

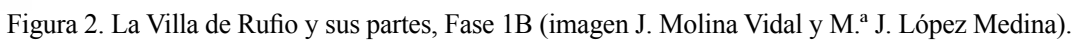


gada referencia en los debates sobre el carácter esclavista de la producción romana de época altoimperial y su alcance cronológico.

La villa de Rufio (Fase 1) se localiza en la ladera oriental de una colina de suave pendiente a la que se adapta mediante una serie de terrazas que permiten salvar los cerca de $8 \mathrm{~m}$ de desnivel total del conjunto, y los cerca de $3 \mathrm{~m}$ de desnivel entre las partes urbana y rustica. De la fase fundacional se distinguen perfectamente las tres áreas de referencia de las villas de esta época (Molina et al., 2017) (Fig. 2):

- pars urbana: área residencial señorial con un balneum situado al SE.

- pars fructuaria: área productiva situada al norte.

- pars rustica: área servil situada al S-SE de la villa.

Nos encontramos ante un modelo de villa concentrado (asimilable al tipo M1.1.1.1 de Álvarez Tortosa, 2017), como ha demostrado el análisis detallado del territorio circundante (Grau y Molina, 2010), delimitando un extenso fundus en el que destaca la ausencia de otros núcleos campesinos cercanos, remarcando su carácter central y unitario. Se trata de un gran complejo productivo de $9.000 \mathrm{~m}^{2}$, que debe su denominación al hallazgo de una inscripción en posición secundaria con formulario Gaio Iulio Rufioni/Nobilis L(ibertus) Posuit (Llidó y Molina, 2012). Suetonio en De vita Caesarum (I, 76) señala a un Rufio como hijo de un liberto muy cercano a Julio César, lo que nos permitiría relacionar a este personaje o un descendiente cercano con el Gaius Iulius Rufio de la inscripción, el dominus de la villa (Fig. 1).

\section{LA PARS RUSTICA Y EL ERGASTULUM (FASE 1)}

El área mejor conservada y casi excavada en su totalidad es el sector S-SE de la villa (Área 1), un edificio independiente conectado estructuralmente al cuerpo central del conjunto de forma tangencial, pero prácticamente aislado de la circulación del resto de pabellones. Sus dimensiones coinciden con las de un $a c-$ tus quadratus y presenta disposición simétrica de espacios entre las mitades E y W (Fig. 2) (Molina et al., 2017). El conjunto presenta una red de canalizaciones y drenajes estructuralmente precedentes a la construcción del edificio que confluye en un gran canal-cloaca que recogía también las aguas del resto de la villa para evacuarlos hacia el valle. Toda esta pars rustica (Área 1) sería un pabellón de dos plantas con la inferior en semisótano, pues se encontraba enterrada en su lado occidental casi tres metros, mientras que en su lado oriental estaría a nivel de suelo exterior (Fig. 3). Amodo de hipótesis presentamos la posible distribución de la primera planta basada en los apoyos arquitectónicos y estructura del área excavada correspondiente al semisótano (Fig. 4). El único acceso documentado con seguridad estaba en la primera planta (Fig. 3 y 4), donde hemos hallado la impronta de un gran umbral que apareció caído en A6. Desde el lado norte A43, de forma acodada, se entraría al conjunto por la cella ostiaria $\mathrm{B} 6-\mathrm{B} 7^{1}$ (Figs. 3 y 4) y se pasaría a B4-B3 hasta el corredor de distribución (B8) que circunda el patio de luces (A9). Desde aquí se accedería al área habitacional de esta primera planta o se podría circular hasta la planta inferior desde B42-B45 bajando a A42-A45 en el semisótano, a modo de doble cella ostiaria, donde se ha documentado la cimentación de una estrecha escalera que comunicaría las dos alturas. Desde A42/45 se accedería a un gran conjunto central formado por un patio cuadrado $(8,20 \mathrm{~m}$ de lado) (A9) de $67,24 \mathrm{~m}^{2}$ circundado por un corredor rectangular (A8) que se extiende hacia otros vestíbulos para crear un amplio circuito formado por la adición de los espacios A8-A12-A15-A22/23-A46-A47-A52-A54-A69. Este patio no era accesible directamente ni transitable, ya que estaba rodeado por un murete sin puertas de 1,50 $\mathrm{m}$ de altura, sobre el que se abren tres vanos por lado. Sobre el murete apoyarían 12 columnas o pilares, 4 por lado, de las que no hemos hallado restos, aunque en los niveles de amortización hallamos restos de capiteles y columnas probablemente de la fase final de la villa, pudiendo ser situadas tanto en el semisótano como en la planta superior. El impluvium no tiene cisterna, ni presenta pavimento y está rodeado de un canal de piedra perimetral con dos sumideros que desaguan en el colector general de la villa. Asimismo, se detecta la existencia de otros cuatro pequeños patios de luces simétricos A21 y A41 (c. $\left.11 \mathrm{~m}^{2}\right)$, por un lado, y A11 y A50 (c. $\left.14 \mathrm{~m}^{2}\right)$ que, junto al mayor (A9) permitirían iluminar y airear todo el semisótano (Fig. 3), mitigando la oscuridad y la humedad de esta planta semienterrada. Los pavimentos han desaparecido, pero los niveles de las zapatas de cimentación de los muros y de la parte superior del sistema de drenaje se hallan a cotas ligeramente más elevadas que los umbrales. La ausencia de restos de mortero o cal en estos umbrales nos ha llevado a plantear la hipótesis de que todo el semisótano estuviera pavimentado en madera.

El análisis de la circulación interior y del mapa jerárquico del conjunto (Hillier y Hanson, 1984, p. 149) nos ha permitido conocer el gradiente de penetración (Rapoport, 1978, pp. 289-298), la profundidad estructural (Blanton, 1994, p. 37), y analizar las relaciones de los distintos espacios (Rapoport, 1978). Su

1 Las numeraciones precedidas de B se corresponden con los ambientes hipotéticos de la primera planta, proyección en altura de los constatados en el semisótano, numerados con la letra A. 

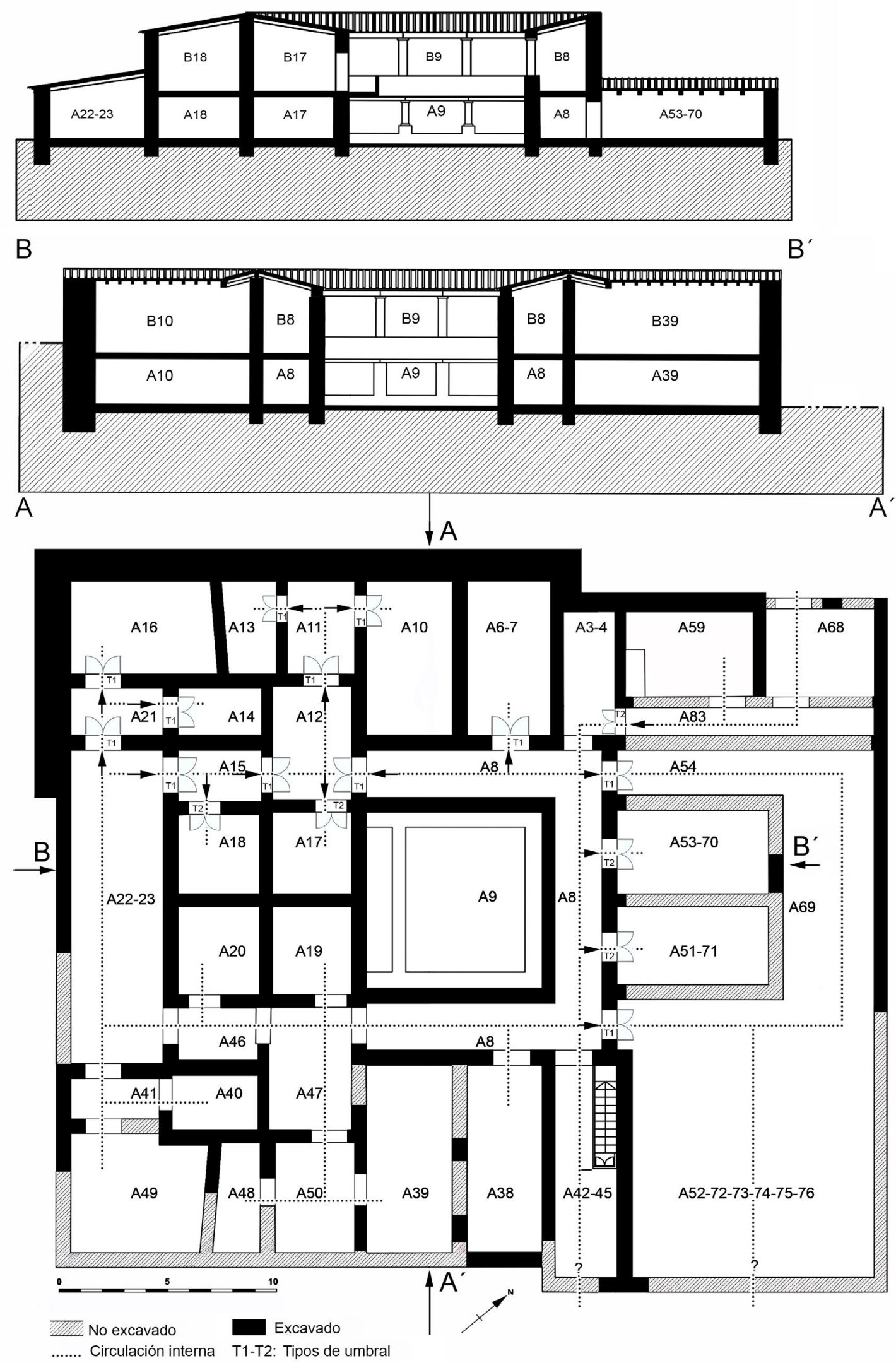

Figura 3. Planta constructiva de la pars rustica y ergastulum, Área 1, Fase 1 (imagen J. Molina Vidal y M. J. López Medina). 


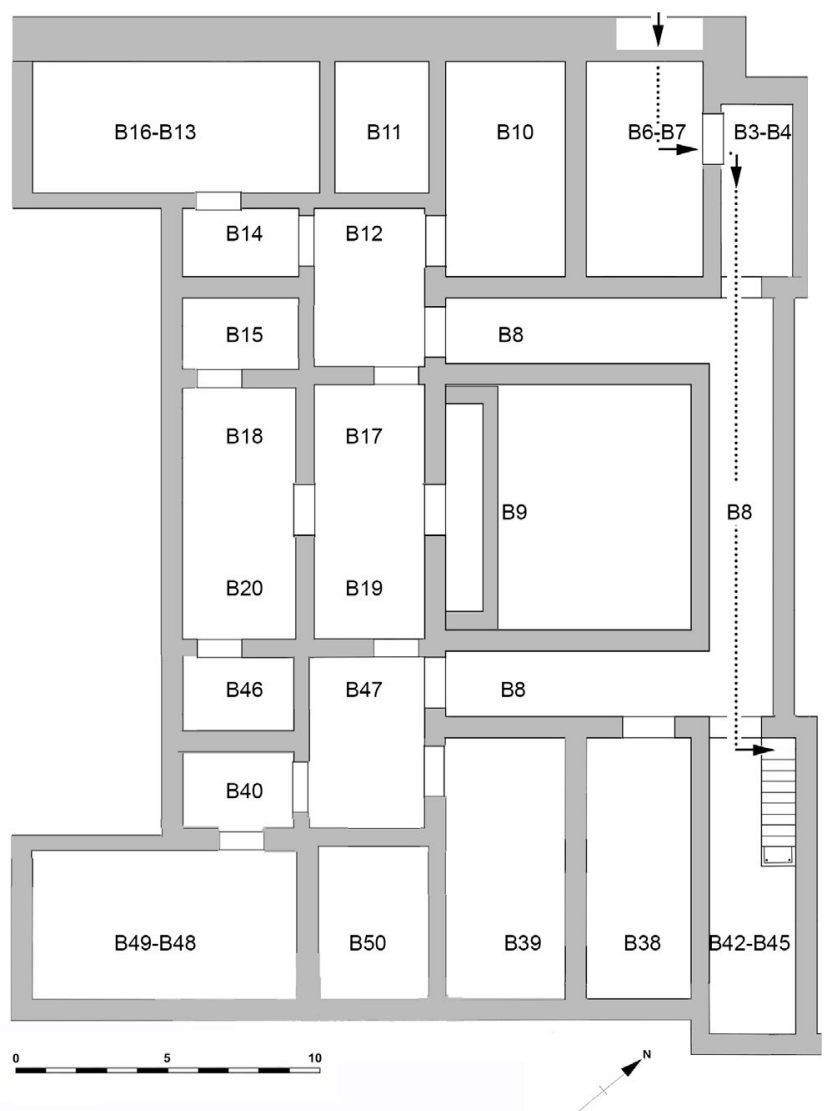

Figura 4. Hipótesis reconstructiva de la primera planta del ergastulum, Área 1, Fase 1 (imagen J. Molina Vidal

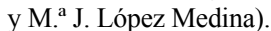

aplicación a la villa de Rufio nos muestra un esquema de accesibilidad atípico para ambientes domésticos romanos, ofreciendo dos conclusiones principales (Molina et al., 2017, p. 399): se pretende eliminar la posibilidad de circular libremente en torno a un ámbito central que diera acceso de forma radial a los habitáculos y se establece una dificultad gradual de acceso a las diferentes habitaciones, llegando a tener estancias solo accesibles tras atravesar cinco puertas (A16, A14 y A40-49). El diseño de este edificio buscaba intencionalmente la fragmentación de la circulación y la reclusión gradual de los habitantes, que quedarían separados por varias puertas que impiden cualquier posibilidad de entrar en contacto.

Internamente la circulación entre la pars urbana y la pars rustica se realizaba al NW del Área 1, donde junto a la culina (A59) se encuentra un pasillo (A83) que enlazaría con unas estancias no excavadas (A68 y A65) que salvarían el desnivel de 4-4,25 m entre ambas partes con una escalera. La cocina (A59) de $22,3 \mathrm{~m}^{2}$ se sitúa junto al balneum, pero en el semisóta- no. Presenta en su lado meridional, único que hemos podido excavar, el banco con la leñera: una estructura rectangular de 2,4 $\mathrm{m}$ de longitud y 0,65 de altura conservadas, con la parte central inferior abovedada y hueca, y la cara superior nivelada y con restos de mortero (Fig. 5). El lado occidental de la cocina de $0,9 \mathrm{~m}$ de amplitud (UE 1054) presenta dos oquedades de tendencia cuadrangular $(0,32 \mathrm{~m}$ de lado y $0.7 \mathrm{~m}$ de profundidad y separadas entre sí $0,4 \mathrm{~m}$ ) que albergarían sendas vigas, a 1,55 $\mathrm{m}$ de altura sobre el nivel de uso, para cocinar y alojar los útiles de cocina.

Todos estos elementos nos han llevado a interpretar este conjunto (Área 1) como el ergastulum o pabellón servil de la villa, tal y como indica Columela (1.6.1), espacialmente diferenciada de la pars urbana y la pars fructuaria, asimilando la pars rustica como el alojamiento de la familia rustica (Dig.50.16.166) (Fig. 2). El pabellón servil era semisubterráneo, cripta como indica Vitrubio (6.8(5).2). De manera explícita, Columela (1.6.3) asocia el ergastulum a un espacio subterráneo para los esclavos encadenados (servi vincti o compediti), aunque debe estar saneado e iluminado por aberturas pequeñas, estrechas y a una altura del suelo que no les deje alcanzar estas con la mano. Los esclavos no encadenados ocupaban otras dependencias que Columela (1.8), de forma genérica, denomina cellae, posiblemente la primera planta de la pars rustica de la villa de Rufio (Molina et al., 2017, p. 401).

Este ergastulum, al menos en la planta subterránea, se diseñaría para albergar un conjunto de esclavos organizados en cuatro grupos, pues tenemos 4 bloques habitacionales, 4 unidades habitacionales y 4 cubicula (Fig. 3):

- Los cuatro bloques habitacionales, situados en las esquinas meridionales del semisótano (A21A14-A16 y A41-A40-A49) y al norte de estos (A11A13-A10 y A50-A48-A39), estaban formados por un pequeño patio (A11 y A50, 11-13 $\mathrm{m}^{2}$ ), al que se abren dos estancias: una pequeña $\left(11 \mathrm{~m}^{2}\right)$ y otra grande $(30-$ $\left.31 \mathrm{~m}^{2}\right)$.

- En torno al patio central (A9) y su corredor circundante (A8) hallamos cuatro unidades habitacionales de 26,5 (A6-7, A53-70 y A51-71) y 28,5 m² (A38) de superficie.

- En el centro de la mitad meridional, la más controlada y menos iluminada y aireada, hallamos un conjunto de cuatro pequeños cubicula de c. $15 \mathrm{~m}^{2}$ (A17, A18, A19 y A20).

Los bloques habitacionales forman un módulo de tres ambientes (patio, estancia pequeña y estancia grande) todos ellos con puerta de acceso y posibilidad de aislamiento. Cabría la posibilidad de que la estancia mayor fuera la habitación donde durmieran los esclavos, mientras que en la menor podría 


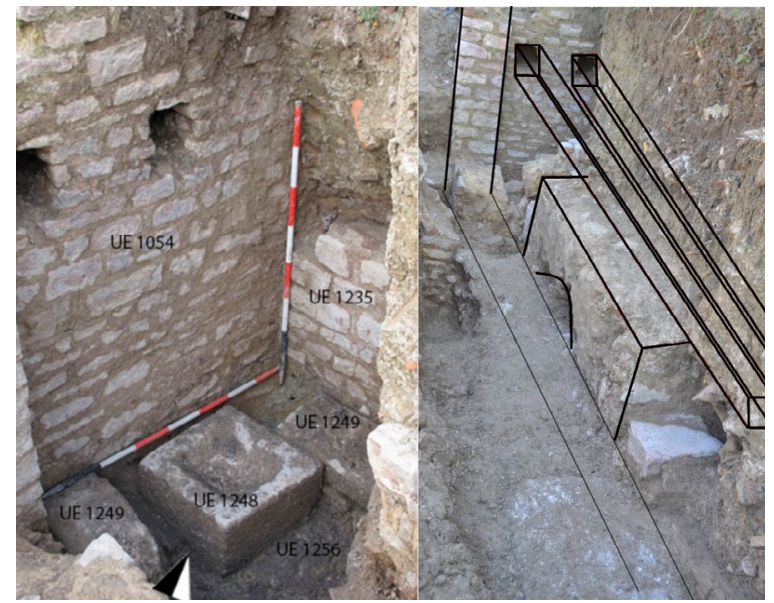

Figura 5. Restos de la culina (A59), con estructuras de la Fase 1 (UE 1054) y Fase 2 (UUEE 1235, 1249, 1248, 1256).

Vista posterior del banco que se apoyaría en el muro del Amb. 3. Con líneas se reconstruyen vigas de madera y se remarcan volúmenes de las estructuras principales

(fotografía-imagen J. Molina Vidal y M. ${ }^{\text {a J }}$. López Medina).

albergar al ergastularius mencionado por Columela (1.8.17). A cada uno de los cuatro grupos le correspondería una unidad habitacional de difícil interpretación funcional (almacén, estancia multiusos o para guardar las herramientas) pues se hallan en la zona menos aislada o controlada del conjunto. Finalmente, los cubicula centrales podrían interpretarse como carceres, prisiones o celdas de castigo, dada su ubicación, aislamiento y grado menor de salubridad (Molina et al., 2017, p. 402).

La existencia de una primera planta es incuestionable, pero la organización y función de sus estancias es difícil de precisar. Sin embargo, parece factible atribuir una capacidad de control visual y de circulación respecto al semisótano, al menos a través de los patios de luces (Fig. 3). A modo de hipótesis podría plantearse que la primera planta alojara al $v i$ licus (área de control) y los servi soluti, al tratarse de la zona menos controlada. Mientras que todo el semisótano podría ser interpretado como el ergastulum, en sentido amplio, es decir, el alojamiento de los servi vincti o compediti, de ahí que los bloques habitacionales tengan una estancia adjunta de control que pudiera ser la habitación del ergastularius. Finalmente, los cuatro cubículos centrales de reducidas dimensiones y menor salubridad podrían ser ergastula, en sentido estricto, cubicula para castigar de forma eventual a esclavos que hubieran de ser penalizados (Molina et al., 2017, p. 402).

\section{LA PARS URBANA (FASE 1)}

La pars urbana (Área 2) (Fig. 2) está formada por un complejo de dependencias y patios $\left(c .775 \mathrm{~m}^{2}\right)$ que se relacionaría directamente y al mismo nivel con un conjunto termal o balneum situado al $\mathrm{N}$ de la pars rustica. El área de entrada de la pars urbana es prácticamente desconocida porque no se ha podido excavar, por lo que solo se puede afirmar que estos espacios responden a un eje transversal (A55-A30-A28): la entrada llevaría a un espacio abierto (A55) no excavado que daría acceso al atrio (A30), parcialmente excavado, del que hemos hallado en posición secundaria los bloques de piedra del impluvium; el larario (A28) fue hallado en buen estado de conservación (Fig. 6); al SE se abría un gran oecus o triclinium (A58); en la parte posterior de A30 hallamos un conjunto de estancias que están sin excavar articuladas por un patio (A34). Finalmente, destaca una serie de cinco habitaciones (A82-A24-A25-A26-A85) abiertas a una logia o pasillo porticado (A84-32) al E, donde el hortus (A61) y las vistas del valle generaban un efecto escénico. Este pasillo (A84-32) conduciría por A65-A68 a la pars rustica, para enlazar con la culina (A58) y el ergastulum (Área 1).

El conjunto de habitaciones (A24-A25-A26-A85) y el oecus/triclinium (A58) estaban pavimentados con mosaicos, que por su uniformidad arquitectónica y la relación constructiva constituyen un conjunto contemporáneo (Fig. 2). En todos los casos, se trata de mosaicos muy finos y de buena factura (módulo 183-197 teselas $/ 100 \mathrm{~cm}^{2}$ ), decorados con motivos geométricos en blanco y negro (Fig. 7), fundamentales para datar la fase 1 de la villa.

En A24 el mosaico presenta el campo (Fig. 8) compuesto por líneas de cuadrados adyacentes, uno de cada dos recargado con un reloj de arena inscrito, en oposición de colores (UE 518) (Balmelle et al., 1985, p. 48; motivo DM 120 g, Rinaldi, 2007, p. 145). Este motivo, claramente inspirado en los revestimientos de opus sectile tallados en sistema modular, es característico del siglo I a. C., frecuente desde mediados del siglo I a. C. en Pompeya (Segundo Estilo) y Hercula$\mathrm{no}^{2}$. En las Regiones I, VIII y X, se hace usual en época

2 Cfr. Ejemplos en Pompeya: Casa dei Vetii VI 15,1: pórtico E del peristilo-1 (PPM V, 502, fig. 54); frigidarium-20 de la Casa del Criptoportico (I 6,2) (Blake, 1930, p. 79; PPM I, 230, fig. 64); oecus tetrastylus-4 y ala-7 Casa delle Nozze d'Argento (V 2, i) (PPM III, 753, fig. 166; 770-771, fig. 201a); ambiente 24 Casa del Centauro (VI 9, 3-5) (PPM IV, 850-851, fig. 62). En Herculano: sala-r del norte del atrio Villa dei Papiri, fase II Segundo Estilo (50-30 a. C.) (Rinaldi, 2007, p. 146; De Simone y Ruffo, 2005, p. 174). 
augustea, y un poco más tarde, entre el final del siglo I a. C. y la mitad del siglo I d. C., el esquema recorre la península itálica (Blake, 1930, p. 79; Rinaldi, 2007, pp. 146-147) ${ }^{3}$. Durante la segunda mitad del siglo I d. C. el motivo se hace menos frecuente y las teselas utilizadas son irregulares y más grandes (Rinaldi, 2007, p. 146; Paolucci, 2012, pp. 138-139).

El borde en sentido directo está compuesto por una banda negra de cuatro filas de teselas y dos bandas

3 En Roma algunos ejemplos del periodo césar-augusteo al cambio de Era se pueden consultar en: Blake, 1930, p. 79; Morricone Matini, 1967, p. 59; Rinaldi, 2007, p. 146. En Aquileia desde finales del siglo I a. C. a principios del siglo I d. C. en: Bueno, Novello y Rinaldi, 2012, pp. 205 y 207. En Vulci durante época julio-claudia en: Rinaldi, 2007, p. 147. O en la Emilia Romagna se datan principalmente en época augustea como se puede ver en: Rinaldi, 2007, p. 147; Paolucci, 2012, AR-122 a-b, BO-14 y FA-29a. blancas, la interior formada por cuatro filas de teselas, y la exterior por tres. Por último, el mosaico está rodeado de una franja de teselas blancas dispuestas en sentido oblicuo (Fig. 8). En el Segundo Estilo (50-30 a. C.) estos bordes solo presentan una banda negra enmarcando al mosaico, como ocurre en un pseudoemblema de la sala-r del norte del atrio de la Villa dei Papiri de Herculano, donde la banda está formada por seis filas de teselas, mientras que en época césaro-augustea la banda tiende a duplicarse (Rinaldi, 2007, pp. 70 y 156). Por otro lado, en el Segundo Estilo las bandas negras suelen ser más anchas (a partir de seis filas dependiendo de la amplitud de la dependencia), y se van haciendo de menor grosor a principios del Tercer Estilo (Guidobaldi, Grandi y Pisapia, 2014, p. 417). Así pues, nos encontramos ante un mosaico de ejecución refinada y altísimo nivel de época augustea (Tercer Estilo Inicial).
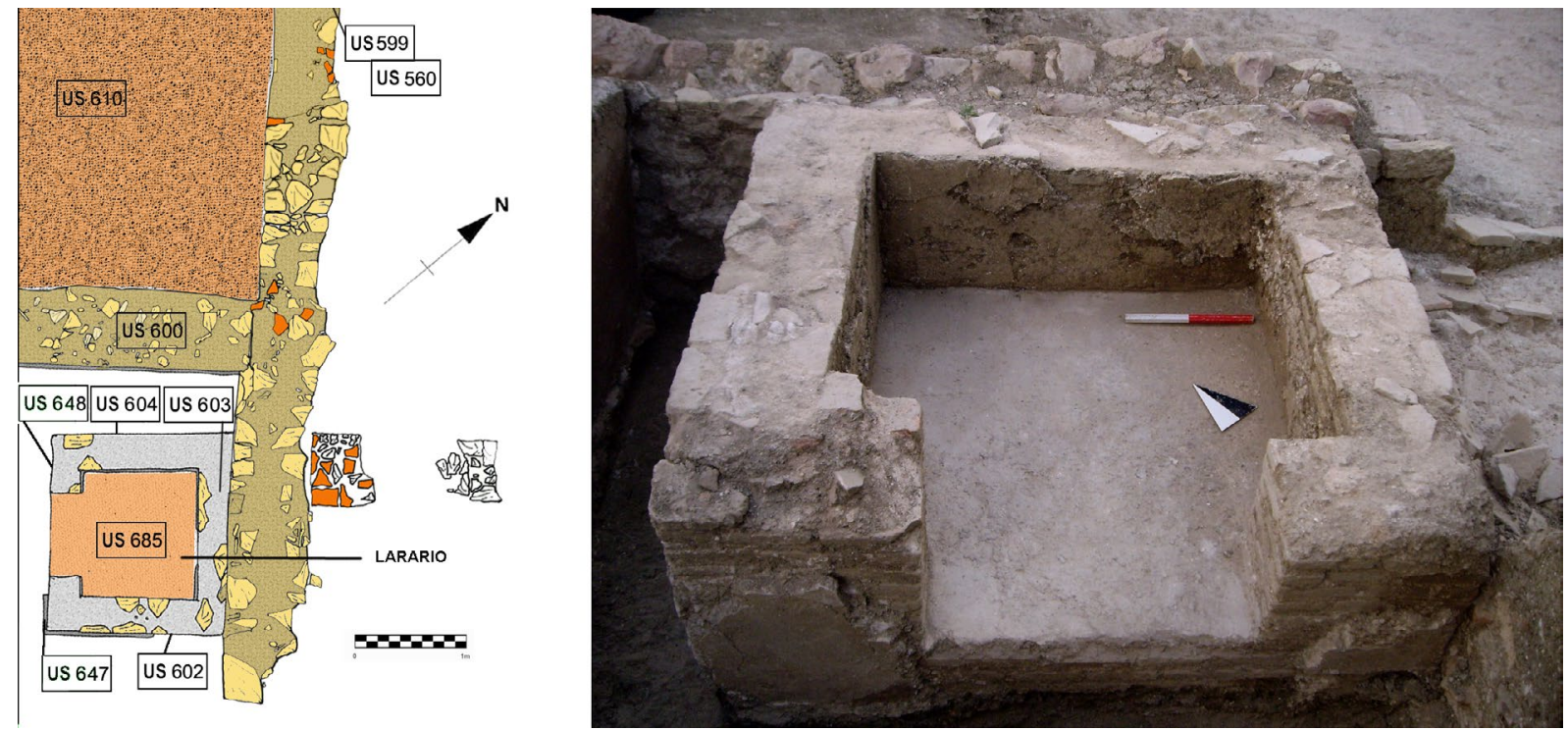

Figura 6. Restos del larario en A28 (UUEE 685-603-604-648-602-647) de Fase 1. Restos de estructuras productivas de la Fase 2 (UUEE 599-

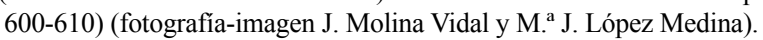

\begin{tabular}{|c|c|c|c|c|c|}
\hline Ambiente & $\begin{array}{c}\text { Módulo: } \\
\text { teselas } / 100 \mathrm{~cm}^{2}\end{array}$ & Motivos & Datación & $\begin{array}{c}\text { Fase } \\
\text { constructiva }\end{array}$ & Área \\
\hline A24 & 197 & Geométricos & Augusto (Tercer Estilo Inicial) & 1 & 2 \\
\hline A25 & 183 & Geométricos & $\begin{array}{c}\text { Augusto (Segundo Estilo-principios } \\
\text { Tercero) }\end{array}$ & 1 & 2 \\
\hline A26 & 183 & Geométricos & Augusto (Tercer Estilo) & 1 & 2 \\
\hline A56 & --- & --- & --- & 1 & 2 \\
\hline A58 & 197 & Geométricos & Augusto (Tercer Estilo inicial) & 1 & 2 \\
\hline A6 & 128 & Figurativo marino & $2^{\mathrm{a}}$ mitad del s. I d.C. & 2 & 1 \\
\hline A7 & 108 & Geométrico & $2^{\mathrm{a}}$ mitad del s. I d.C. & 2 & 1 \\
\hline
\end{tabular}

Figura 7. Características generales de los mosaicos hallados en la Villa de Rufio. 

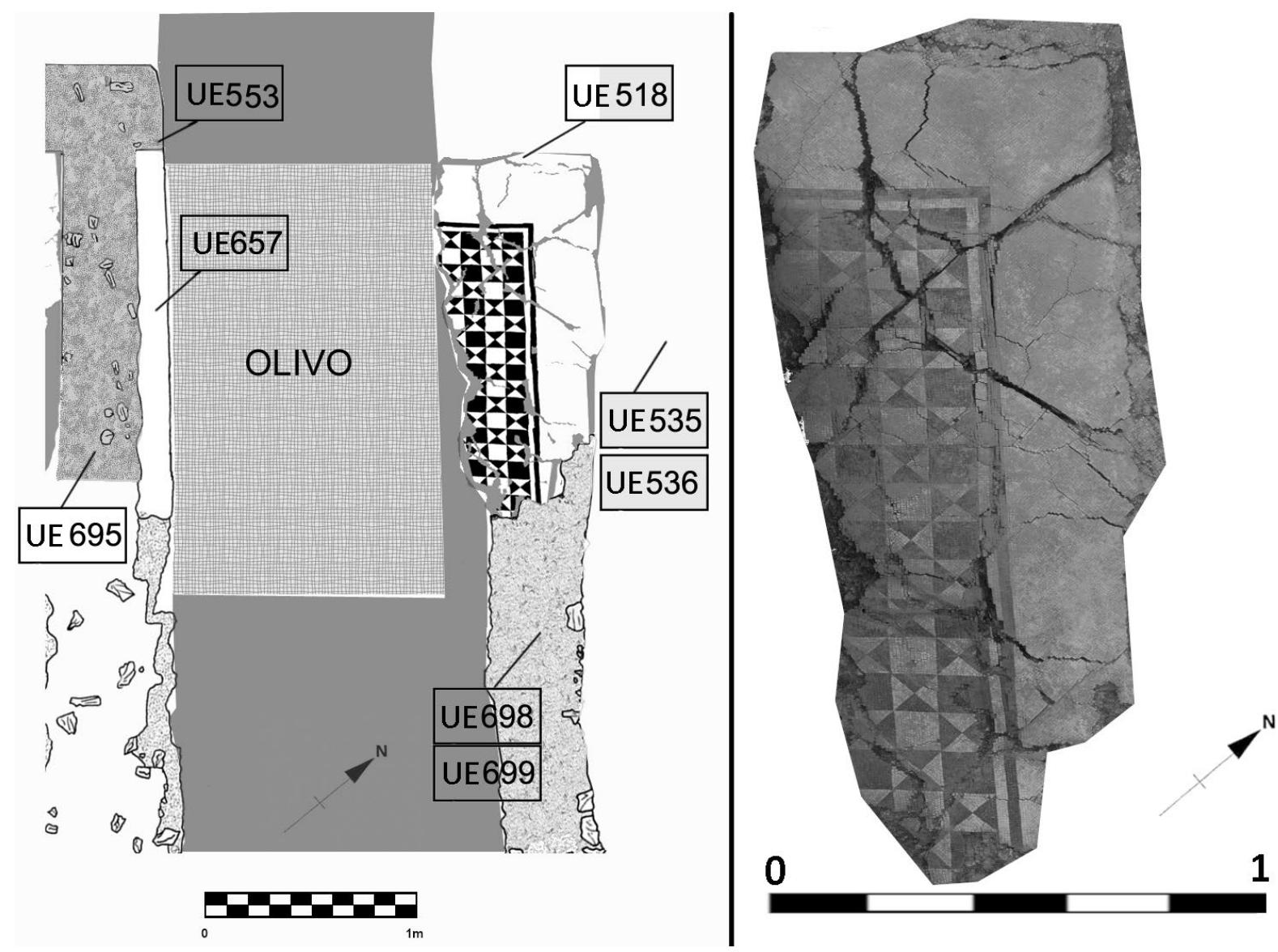

Figura 8. Mosaico de A24 (Fotografia-imagen J. Molina Vidal y M. a J. López Medina).

La estancia A25 destaca por conservar todavía el inicio de los muros de tierra (UUEE 553-556-695) enlucidos de color rojo (UE 557) (Fig. 9), como probablemente ocurría con la tabiquería del resto de las estancias de esta serie. El borde en orden directo está formado por una banda negra compuesta por tres filas de teselas, enmarcada por dos bandas blancas de tres filas de teselas cada una. Por último, el mosaico vuelve a estar rodeado de una franja de teselas blancas dispuestas en sentido oblicuo (UE 675-697).

El campo (Fig. 9) muestra una red de círculos enlazados blancos sobre fondo negro que determinan cuadrados curvilíneos negros sobre los que se inscriben cuadrados blancos (Balmelle et al., 1985, p. 372; motivos DM 237b/g y 238e/f, Rinaldi, 2007, p. 173). Este tipo de círculos entrelazados se documentan en el siglo I a. C., con teselas de pequeño tamaño de 0.4 a 0.5 (Blake, 1930, p. 83). El esquema de base deriva de prototipos itálicos elaborados en la primera mitad del siglo I a. C. y es frecuente a partir del siglo I a. C. (Rinaldi, 2007, p. 176), como podemos ver en Pompeya o Herculano, coincidiendo con el Segundo Estilo y principios del Tercero 4 , o Aquileia, Emilia Romagna y Veneto, que en su mayoría parecen tener una cronología más tardía de finales de siglo I a. C. o principios del I d. C..$^{5}$ Otro paralelo muy similar, aunque no lleva los cuadrados inscritos blancos sobre los curvilíneos negros, sería el mosaico de la villa de Horacio (segundo ambiente, dependencia 1) datado en la primera mitad del siglo I d. C. (Werner, 2006, I p. 256; II, D.8).

$4 C f$ r. Algunos ejemplos en Pompeya: umbral del ala-54 junto al atrium Casa del Citarista (I 4,5.24) (PPM I, 174, fig. 94); umbral del triclinio-5 Casa della Venere in conchiglia (II 3, 3) (PPM III, 124-125, fig. 18); umbral del triclinio-n Caserma dei Gladiatori (V 5, 3) (PPM III, 1079-1080, figs. 22 y 24); triclinio-7 Casa di Campionnet I (VIII 2, 1) (Blake, 1930, pp. 83, 96-97; PPM VIII, pp. 32-33, fig. 7). En Herculano: umbral entre el atrio y el oecus 7 Casa del Colonnato Tuscanico (VI, 16-17, 18, 26) (Guidobaldi, Grandi y Pisapia, 2014, pp. 364-365); biblioteca de la Villa dei Papiri (Pisapia, 2004, p. 69; Guidobaldi, Grandi y Pisapia, 2014, pp. 364-365).

5 Cfr. Aquileia: Bueno et al., 2012, pp. 207-208. Emilia Romagna: Paolucci, 2012, BO-27 y FC-01. Veneto: Rinaldi, 2007, p. 176. 

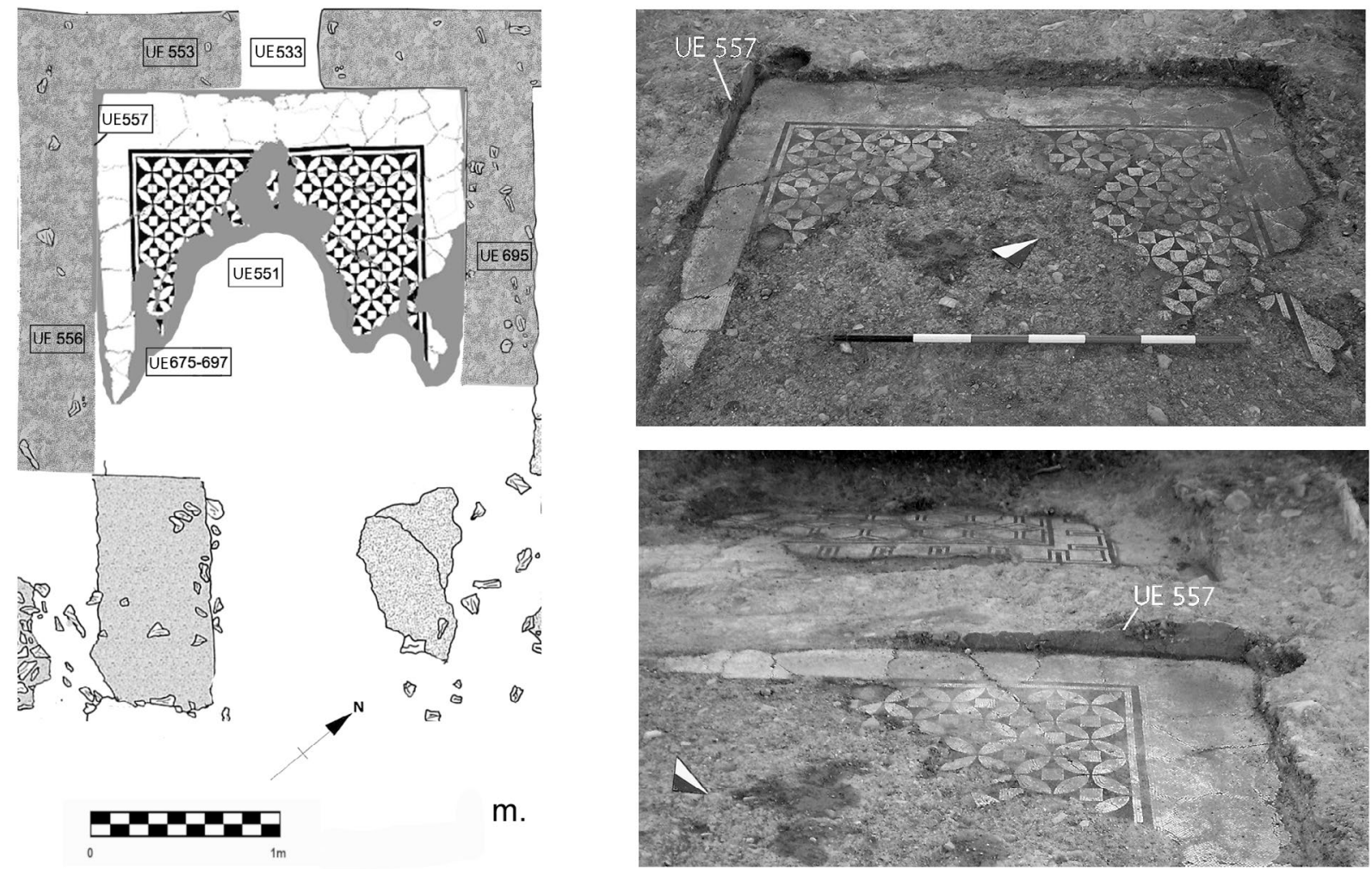

Figura 9. A25: mosaico (UE 675-697) y detalle de muros de tierra (UUEE 556-553-695) enlucidos (UE 557)
(fotografia-imagen J. Molina Vidal y M. ${ }^{\text {J. L. López Medina). }}$

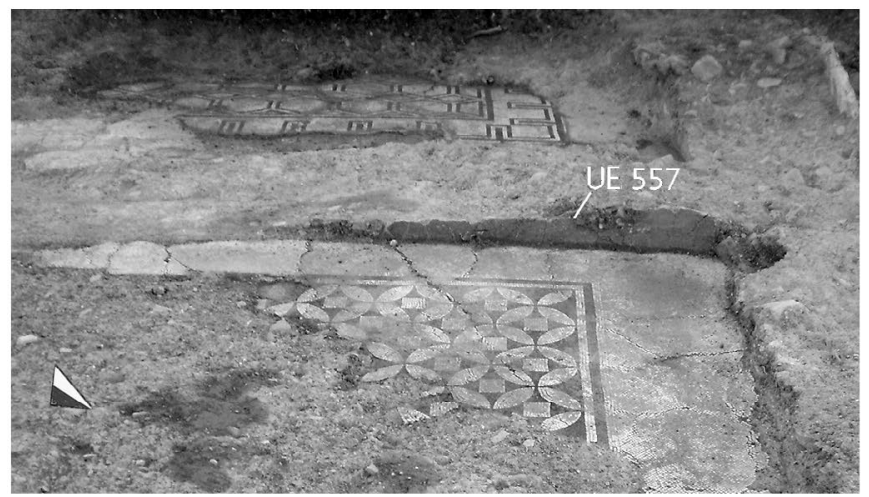

Se trata, pues, de uno de los esquemas geométricos más difundidos en el tiempo y espacio (Rinaldi, 2007, pp. 173, 175-176). Los motivos geométricos de A24 y A25, con ligeras variaciones, se han localizado en la Casa del Marinaio (VII 15, 2) en Pompeya datados en época tardorrepublicana (Segundo Estilo) (PPM VII, p. 722, fig. 35; pp. 729 y 731, figs. 48, 49 y 52), y con la misma cronología en la Villa dei $\mathrm{Pa}$ piri en Herculano (Pisapia, 2004, p. 69; De Simone y Ruffo, 2005, p. 174; Rinaldi, 2007, p. 146; Guidobaldi, Grandi y Pisapia, 2014, pp. 364-365). En conjunto se trata de un mosaico que presenta características, material y módulo semejantes a los de A24, por lo que su cronología también sería augustea.

En A26 el borde de interior a exterior está formado por una banda compuesta de dos filas de teselas blancas y otra de tres filas de teselas negras (UE 696) (Fig. 10). A continuación, se localiza una greca negra sobre fondo blanco, para terminar de nuevo con una banda de tres filas de teselas negras y otra formada por tres filas de teselas blancas. Esta greca es un motivo irregular bícromo, cuyo resultado es una banda de torres y una línea dentellada (Rinaldi, 2007, p. 42). El mosaico vuelve a estar rodeado por una franja de teselas blancas dispuestas en sentido oblicuo.
El campo (Fig. 10) está decorado con una composición romboidal de hexágonos y rombos adyacentes delineados en negro sobre fondo blanco. Los rombos se transforman en triángulos en la fila externa y los hexágonos en cuadriláteros (Balmelle et al., 1985, p. 332; motivo DM 213A, Bueno, 2011, p. 274). La singularidad de esta composición del mosaico de A26 se basa en la individualización de cada uno de los hexágonos y de los rombos (así como de los cuadriláteros y los triángulos) que están delimitados por una línea negra de dos filas de teselas, dejando entre ellos un espacio formado por dos filas de teselas blancas. Este mosaico presenta una composición de panal de abejas formada solo por hexágonos ampliamente documentada a partir de la primera mitad del siglo I a. C. en los pavimentos de mortero, donde los hexágonos y rombos están delineados mediante teselas, la mayor parte de los ejemplos se concentran en el área pompeyana (Bueno, 2011, pp. 274-275) ${ }^{6}$. A partir de los

6 Cfr. Algunos ejemplos en Pompeya son: tablinium-7 Casa dell Bell'Impluvio (I 9, 1) (PPM I, p. 926, figs. 10-11); exedra-Z' Casa del Marianio (VII 15, 2) (PPM VII, p. 747, fig. 84); triclinium-6 Casa del Cinghiale (VIII 2, 26.27) (PPM VIII, p. 217, fig. 51). En Herculano: sala D Casa dell'Arbergo (III, 1-2, pp. 18-19) (Guidobaldi, Grandi y Pisapia, 2014, pp. 139-140). 

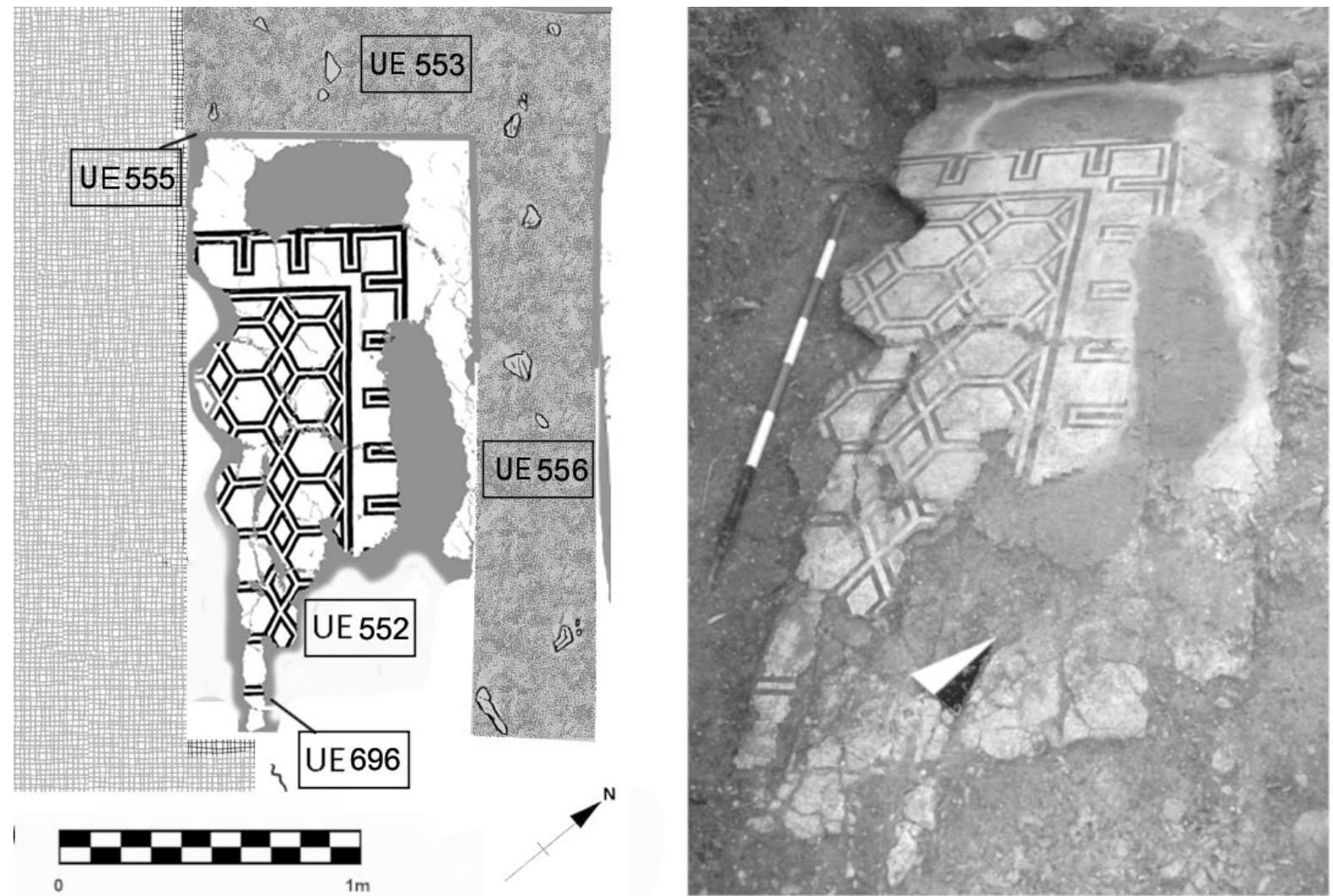

Figura 10. Mosaico de A26 (fotografía-imagen J. Molina Vidal y M.a J. López Medina).

primeros años del siglo I d. C. se hace en mosaicos, sobre todo en el área centro-itálica ${ }^{7}$. En estos el motivo aparece simplemente delineado en negro sobre fondo blanco, y se utiliza la misma línea para trazar los hexágonos y los rombos, con el paso del tiempo el relleno también recibe decoración, y esta se hace más compleja y polícroma en el siglo IV d. C. (Bueno, 2011, p. 275).

La delimitación de las figuras geométricas individual con hexágonos y rombos la encontramos en mosaicos tardíos polícromos como el del pórtico del ambiente 1-área A de la Villa Ossaia de Cortona, datado en la primera mitad del siglo IV d. C. (Bueno, 2011, p. 110), además presenta decorado el relleno de los hexágonos. Esta delimitación de figuras geométricas en mosaicos en blanco y negro tiene un paralelo en el pavimento del triclinio-17 de la Casa dei Cubicoli floreali (I 9,5) de Pompeya, si bien la red es de hexágonos, cuadrados y estrellas de cuatro puntas, y se data en época julio-claudia, correspondiendo al Tercer Estilo (PPM II, p. 137, fig. 174).

7 Cfr. Roma y sus alrededores (Bueno, 2011, p. 275): Villa di Lunghezzina, Domus di S. Pudenziana, Columbario dei Liberti di Livia, o el Santuario de Bona Dea en Ostia.
El borde con variantes está documentado entre la mitad del siglo I a. C. y el siglo II d. C. (Rinaldi, 2007, pp. 42-43), así el de A26 es igual al del mosaico del triclinio-6 de la Casa di Apollo e Coronicle (VIII 3, 24) de Pompeya, que se data a mediados del siglo I a. C. (PPM VIII, p. 420, fig. 4). Sin línea dentellada se localiza en territorio sabino en uno de los pavimentos del complejo público de carácter forense de Forum Novum datado entre el periodo cesariano y finales del siglo I a. C. (Alvino, 1995, p. 506; Rinaldi, 2007, p. 42). A principios del siglo I a. C. se ha documentado en Vicolo Adigetto (Verona), donde delimita el campo central blanco del mosaico, y presenta en el relleno del borde cruces (Rinaldi, 2007, pp. 42-43).

De igual forma que ocurre en los ambientes anteriores, este motivo, pero sobre mortero, se localiza también en la Casa del Marinaio (VII 15, 2) en Pompeya, en concreto en la exedra-z' (PPM VII, p. 747, fig. 84), y se data en época tardorrepublicana, aunque en mosaico no se documenta hasta los principios del siglo I d. C. Por otro lado, la delimitación de las figuras individualizadas del campo la hemos documentado en el Tercer Estilo, y el borde presenta un paralelo en la Casa dei Cubicoli floreali $(\mathrm{I}$ 9, 5) de Pompeya de época tardorrepublicana. Todo ello nos permite 
deducir que el mosaico debe corresponder al Tercer Estilo, presentando la misma cronología augustea.

En A56 se ha localizado otro pavimento de mosaico de factura similar a los anteriores pero muy deteriorado por las fosas de viña y olivo modernas. El mosaico está enmarcado por varias filas de teselas blancas y negras dispuestas en orden directo que a su vez están rodeadas por una banda de teselas blancas dispuestas en sentido oblicuo, que muestra el inicio del campo (UUEE 1033-1061) (Fig. 11).

A58 es una estancia de mayores dimensiones que el resto, lo que junto a su ubicación nos permite interpretarlo como un oecus o un triclinium. El campo está formado por una composición reticulada de estrellas de ocho rombos tangentes blancos delineados en negro que determinan cuadrados en ángulo de $45^{\circ}$ (Fig. 11) (Motivo DM173e, Rinaldi, 2007, p. 101). Los cuadrados de mayor tamaño se van alternando en diagonal formando una composición con una fila ornamentada con cuadrado central y triángulos en negro sobre fondo blanco, y otra fila con un cuadrado cóncavo o curvilíneo inscrito en blanco sobre fondo negro. Los pequeños presentan a su vez un cuadrado en negro sobre fondo blanco. En la base del cuerpo central, junto al borde, se forman grandes triángulos con tres más pequeños inscritos sobre fondo blanco. La disposición de las teselas se adapta a los diversos dibujos geométricos.

El borde está formado por ocho bandas (desde el interior hasta el exterior) (Fig. 11): una formada por dos filas de teselas negras, otra de cinco filas de tese- las blancas, la siguiente presenta cuatro filas de teselas negras, seguida de cinco filas de teselas blancas, que enmarcan la banda central que tiene representada una trenza de dos cabos en oposición de colores (Motivo DM 70d, Rinaldi, 2007, p. 33). A continuación, la estructura se repite en sentido inverso con una banda de cinco filas de teselas blancas, seguida de cuatro filas de teselas negras, y la última está formada por tres filas de teselas blancas; en esta parte del mosaico las filas de teselas se disponen en orden directo, salvo las de la trenza que se adaptan al dibujo. Por último, el mosaico está rodeado de una franja de teselas blancas dispuestas en sentido oblicuo o indirecto.

La red de estrellas de ocho rombos y cuadrados del campo es un motivo frecuente, con múltiples variaciones, desde la segunda mitad del siglo I a. C., y sobre todo en el siglo I d. C. (Blake, 1930, p. 111; Guidobaldi, Grandi y Pisapia, 2014, pp. 325-326). Su origen está en la decoración de los pavimentos de mortero con el motivo de la estrella de finales del siglo II y principios del I a. C., que pasa al mosaico durante el Segundo Estilo ${ }^{8}$. Posteriormente se difun-

$8 C f r$ Ejemplos en Pompeya: una sola estrella como motivo central en el tablinium-j Casa di Cerere (I 9,13) (PPM II, p. 217, fig.70); umbral del tablinium-i Casa di Caecilius Iucundus e casa anessa (V1, 26 y V1, 23) (PPM III, pp. 586-587, figs. 19 y $21)$; con motivo central estrellas pero sin cubrir todo el campo en el tablinium-e Casa degli Amorini dorati (VI 16, 7.3) (PPM V, pp. 738-739, figs. 43-45).
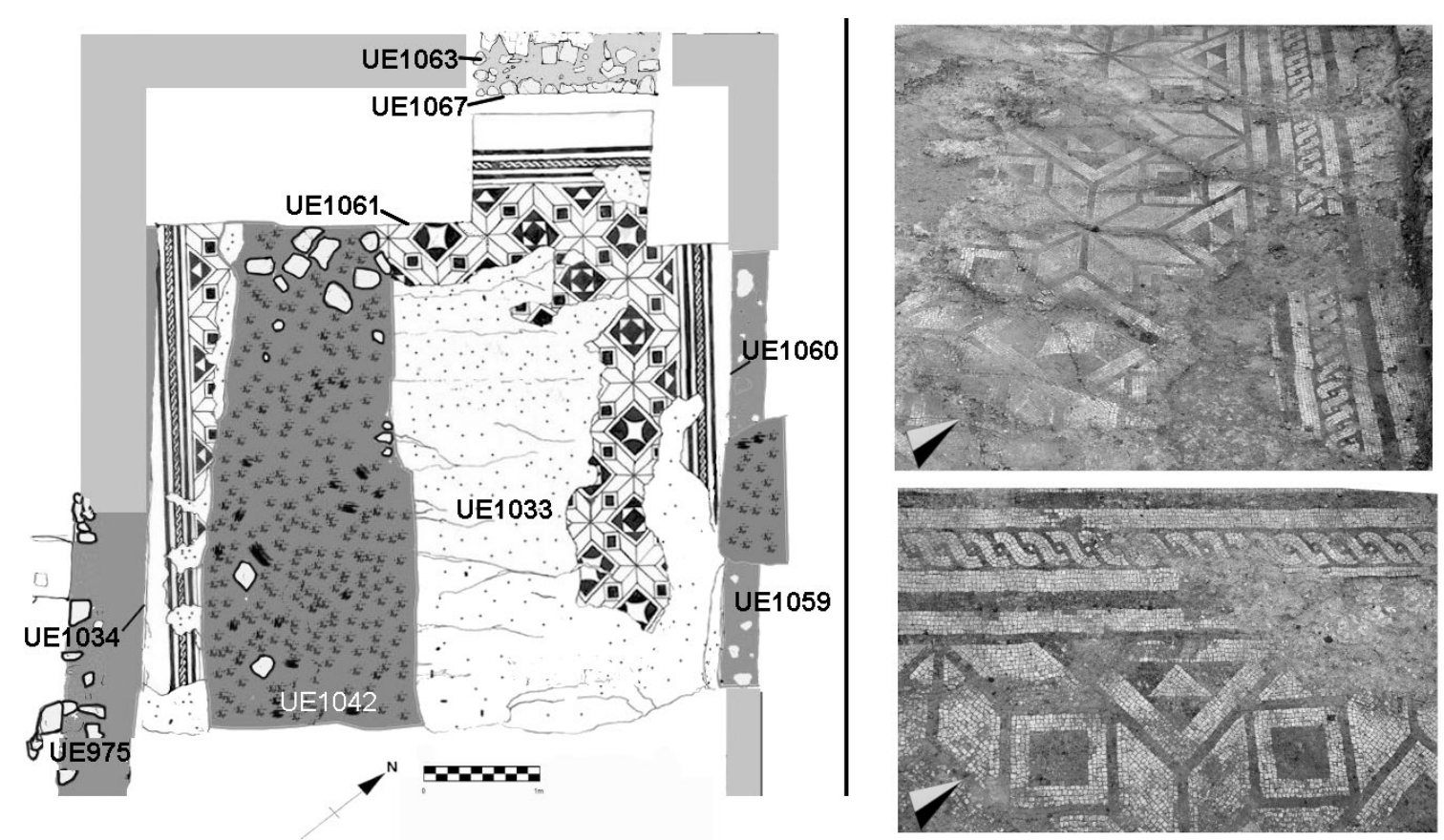

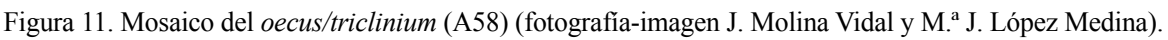


de durante los ss. I-II d. C., perdiendo importancia en momentos posteriores (Lugari y Grandi, 2004, p. $442)^{9}$. El modelo con estrellas blancas y cuadrados en diagonal se localiza en las Regiones I, VI y V en época augustea y no se vuelven a encontrar hasta el siglo II (Regiones VI y V: Gubbio, Matelica y Villa Patenza en Macerata), aunque más articuladas en el relleno de los cuadrados, frente a la linealidad utilizada en el periodo augusteo (Werner, 2006, I, p. 255; Rinaldi, 2007, pp. 101-102).

Pese a las diferencias, pues los cuadrados de mayor tamaño no van en diagonal, hay que destacar su similitud con el mosaico del ambiente 8 de la Villa de Volusii en Lucus Feroniae (Fiano Romano), datado entre 10 a. C. y 20 d. C., pues destaca la linealidad de los motivos geométricos en las intersecciones (Moretti y Sgubini, 1977, p. 26; Dunbabin, 1999, p. 58). Según M. Moretti y A. M. Sgubini Moretti (1977, p. 26) la compleja organización de la decoración y algunos

9 Variantes de este motivo se localizan Roma y área centro-itálica de inicios del periodo imperial destacan: pavimento del androne del Museo delle Terme (Roma) (Blake, 1930, p. 111); villa della Lunghezzina (Rinaldi, 2007, p. 101). Del siglo I d. C.: Domus Fulminata (Ostia) (Becatti, 1961, I, p. 106); ambiente 35 Villa di Castel di Guido (De Franceschini, 2005, p. 158). Del siglo II d. C.: ambientes 7, 8 y 19 de los Hospitalia de la Villa Adriana (De Francescini, 1991, pp. 41, 42, 48 y 371); ambiente 1 de la Villa de Horacio (Werner, 2006, II D.8) con campo de las estrellas en negro y un módulo de 120-130 teselas/100 cm² (Lugari y Grandi, 2004, p. 445).

FASE 1A

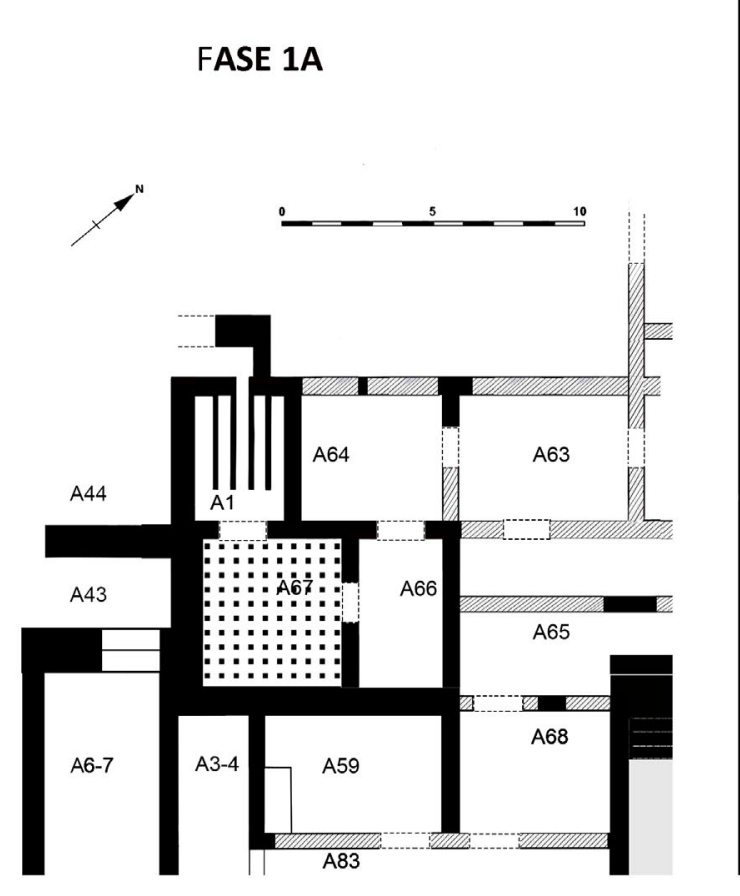

motivos del repertorio se pueden confrontar con ejemplares de Ostia en la Domus Fulminata y en la Insula delle Muse. Es importante saber que el motivo de la estrella realizada con rombos se encuentra por primera vez como modelo para un pavimento entero en el mosaico de Lucus Feroniae, que también presenta una buena factura (146 teselas $\left./ 100 \mathrm{~cm}^{2}\right)($ De Franceschini, 2005, pp. 275-276; Werner, 2006, I, 258).

Otros paralelos datados en época augustea son los localizados en un contexto residencial privado de la via degli Ortacci de Gubbio (Perugia) (Rinaldi, 2007, p. 101), y en Villa Albrizzi de Este (Chiesa degli Zoccoli) (Blake, 1930, p. 112; Rinaldi, 2007, p. 502).

El motivo de los cuadrados pequeños lo tenemos documentado en relación con el de la estrella en el umbral del tablinium-i de la Casa di Caecilius Iucundus e casa anessa (V 1, 26 y V 1, 23) (PPM III, pp. 586-587, figs. 19 y 21) y en la Villa Albrizzi de Este (Rinaldi, 2007, p. 502). El motivo de los cuadrados de mayor tamaño con cuadrado central y triángulos en negro sobre fondo blanco se documenta en el mosaico de la Villa Albrizzi de Este de época augustea, pero alterna con uno decorado con una flor (Blake, 1930, p. 112; Rinaldi, 2007, p. 502). El que alterna cuadrados curvilíneos, como es nuestro caso, se suele utilizar junto con otros elementos y ya se halla en el Segundo Estilo en Oplontis, en Pompeya son característicos del Tercer Estilo y está ampliamente difundido en el Cuarto.

El motivo de la trenza en el borde no presenta límite de tiempo y espacio, siendo más usual en los bordes

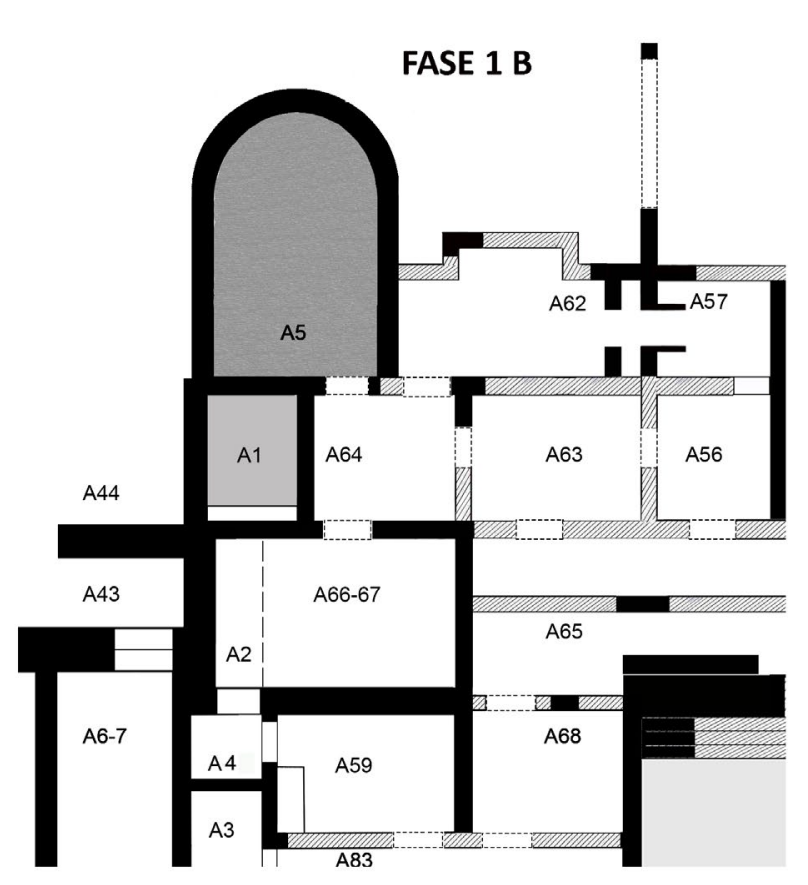

Figura 12. Planta del balneum, Fases 1A y 1B (imagen J. Molina Vidal y M. ${ }^{\text {a }}$. López Medina) 


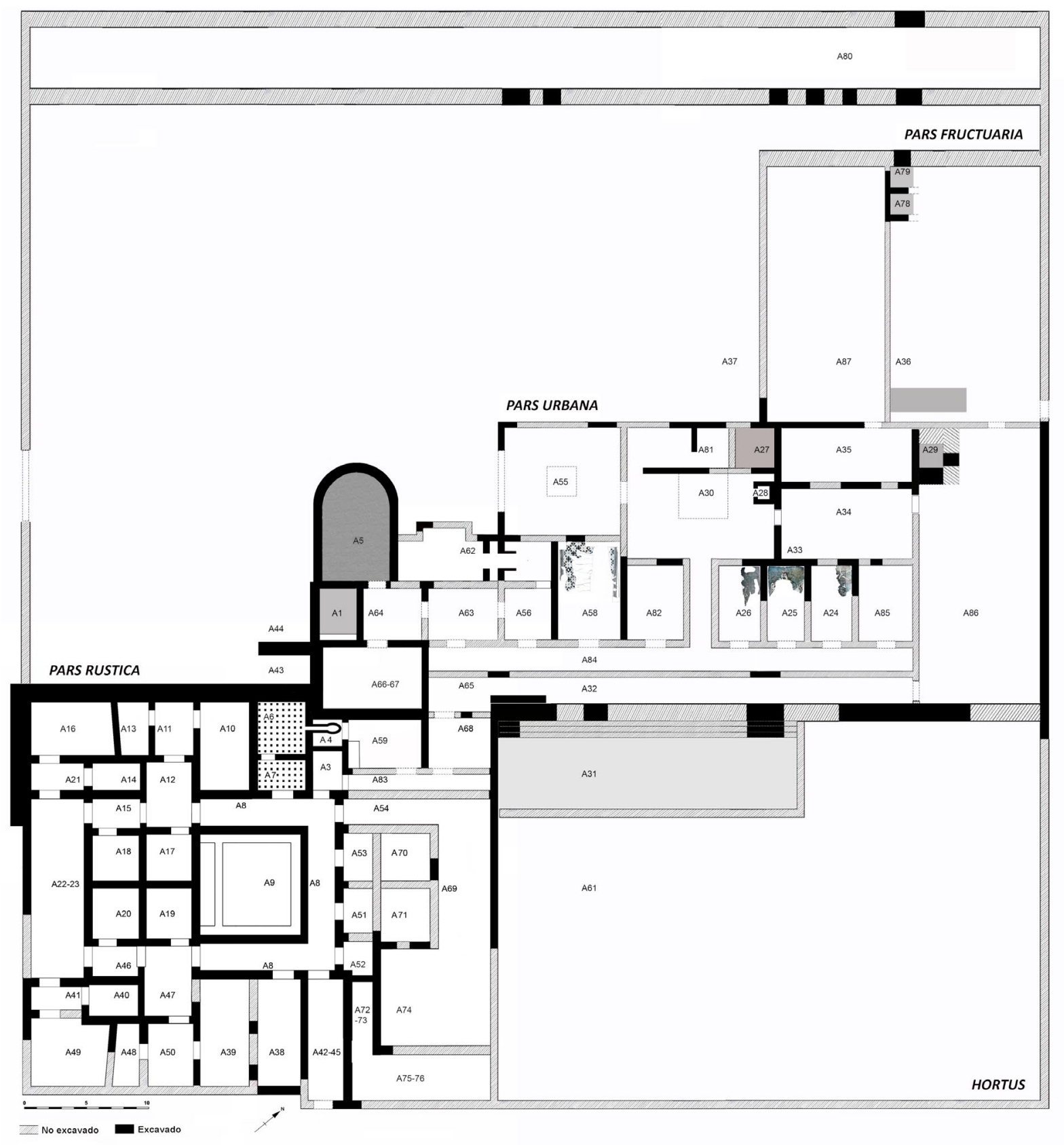

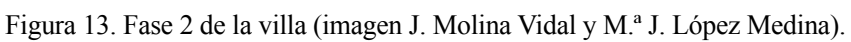

del impluvium (Rinaldi, 2007, pp. 33 y 35; Guidobaldi, Grandi y Pisapia, 2014, pp. 51 y 297). En blanco y negro se utiliza a partir de mediados del siglo I a. C., destacando el paralelo de la Villa Albrizi de Este, cuya datación es de inicios del siglo I d. C. (Rinaldi, 2007, p. 502). Por lo tanto, nuevamente estaríamos ante un mosaico de época augustea (Tercer Estilo inicial).

Al SE del conjunto residencial, entre la pars rustica y la urbana, junto a su entrada principal, hallamos un conjunto termal o balneum, parcialmente excava- do, que consta de dos fases (1A y 1B) (Fig. 12). La primera fase (1A) presenta unas dimensiones menores con, al menos, un praefurnium al NW del caldarium (A1-A67). A modo de hipótesis y a falta de concluir su excavación, el complejo termal estaría constituido por el frigidarium (A64), el tepidarium (A66) y el caldarium (A67) que podría presentar una sudatio o laconicum (A1). Posteriormente, este balneum se reestructura y se amplía considerablemente con la construcción un gran frigidarium (A5) de planta absidiada 

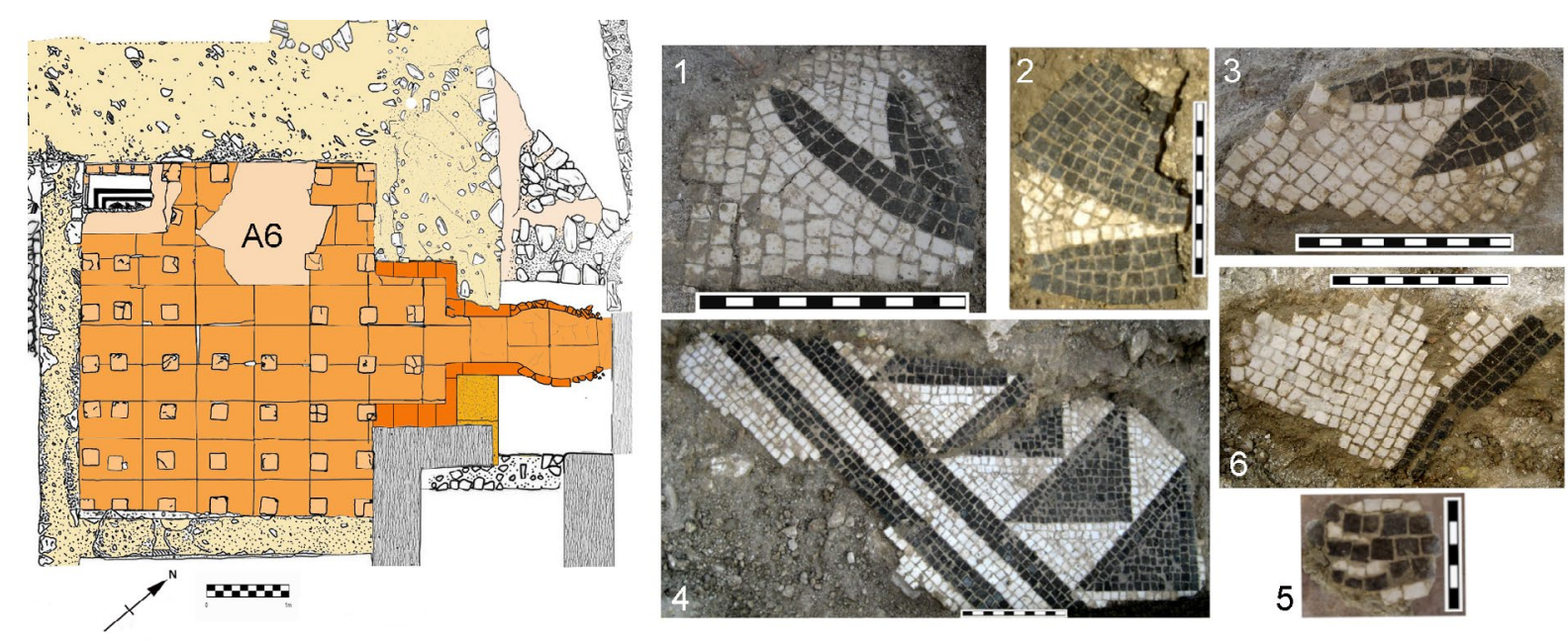

Figura 14. Mosaico de A6 (fotografía-imagen J. Molina Vidal y M. a J. López Medina).

y pavimentación de opus spicatum con un pequeño balneum calefactado (A1). Se constata la existencia de dos praefurnia: A2 totalmente nuevo y accesible desde el ergastulum, y A57, que no es descartable que ya existiera en la fase 1. El caldarium estaría en A62, el tepidarium en A64, sin que podamos confirmar la posible inclusión en los baños de A63. La fase 1B de reestructuración del conjunto termal es estructuralmente anterior a la fase 2 datada en la segunda mitad del siglo I d. C. Los datos parciales ofrecidos por la excavación y la presencia de paramentos de opus reticulatum en A5, A57 y A62, nos llevarían a una cronología tardoaugustea, a lo sumo tiberiana, para la ampliación de las termas.

\section{LA REESTRUCTURACIÓN DE LA VILLA (FASE 2)}

La villa de Rufio presenta una fuerte fase de reestructuración (Fase 2) que afecta a espacios de toda la construcción y que señalaría una extensión de las áreas productivas en detrimento de las señoriales, que podrían incluso haber desaparecido (Fig. 13):

- En el Área 2 se detecta una reducción de la pars urbana por la ampliación de la pars fructuaria con la amortización de parte del atrio/peristilo A30 y la construcción de nuevos espacios (A81) y balsas (A27) (Fig. 6), o la compartimentación de A34, y construcción de A35 y A33.

- En la pars fructuaria se documentan reparaciones generalizadas en los pavimentos de opus spicatum (A29).

- El conjunto termal se amortiza, llegándose a sellar el hypocaustum del balneum calefactado y repavimentándolo para convertirlo en un depósito de agua (A1); y se tapia y amortiza el praefurnium de fase $1 \mathrm{~B}$ (A2).
Asimismo, en la pars rustica se detecta una reestructuración total del conjunto que deja de utilizarse como ergastulum, pasando a dedicarse a almacenes $\mathrm{y}$ vivienda del vilicus/procurator de la finca, con la construcción de un modesto complejo termal (Fig. 13). Muy probablemente este departamento (Área 1) en la fase 2 ya no presentaba dos alturas, dado que al construir las termas (A6-7) se elevan los niveles de pavimentación dejando sin altura suficiente los ambientes del antiguo sótano respecto a los niveles de uso de la primera planta en la fase 1. En conjunto observamos que:

- Aparece una reestructuración general de los espacios marcando una fase constructiva de opus mixtum.

- Se reforma el patio A9 y se dividen algunos espacios adyacentes (A53-70 y A51-71).

- En A14 se halla fragmentada y reutilizada como piedra de una estructura interna la inscripción dedicada a Gaius Iulius Rufio.

- De especial interés es la construcción de un pequeño balneum dotado tan solo de caldarium (A6) y tepidarium (A7), y que inutiliza y cambia de función el sótano del ergastulum. Se trata de dos salas dotadas de hypocausta alimentados desde un nuevo praefurnium construido en A4 y pavimentadas en opus tesellatum. La datación de estos mosaicos de nuevo será fundamental para datar esta fase constructiva.

El mosaico del caldarium (A6), documentado in situ en su ángulo W (Fig. 14) y en múltiples fragmentos en niveles de derrumbe, está realizado en blanco y negro, con un módulo de c. 128 teselas $/ 100 \mathrm{~cm}^{2}$. El campo presenta motivo figurativo, con las teselas adaptadas al contorno de las figuras, observándose una gradación en el tamaño de las teselas para mejorar el contorno, dando así mayor precisión al diseño 
figurativo. De este motivo se han podido identificar algunas partes, entre las que destaca la aleta caudal posiblemente de un delfín (Fig. 14-1), así como las aletas pectorales o dorsales (Fig. 14-2 y 3). Otro motivo posible es una figura humana, del que se conserva un fragmento que corresponde a una mano donde se ven tres dedos (Fig. 14-5) y parte de una posible pierna (Fig. 14-6). También se detecta un perfil recto que podría pertenecer a un útil, posiblemente el asta de una lanza o un tridente. Por lo tanto, estamos ante un motivo marino, propio de ambientes termales.

El borde presenta una banda con las teselas dispuestas en orden directo, formada por una composición de triángulos o espinas rectilíneas cortas, en oposición de colores (Motivo DM 11d, Rinaldi, 2007, p. 30; Bueno, 2011, p. 204), que se convierten en cuadrados en las esquinas para adaptarse a ellas. A su vez están enmarcados a cada lado por dos bandas negras de tres filas de teselas, separadas por una banda blanca de tres filas de teselas. Hacia el exterior está encuadrado por una banda de tres filas de teselas blancas y, finalmente, una franja de teselas blancas dispuestas en sentido oblicuo (Fig. 14-4).

Los mosaicos en blanco y negro de tema figurativo empiezan a aparecer en Italia a finales del siglo I a. C. (Clarke, 1979, p. 58) y presentan mayor expansión a partir de las tres o cuatro últimas décadas antes de la destrucción de Pompeya. Según J. R. Clarke, para poder datarlos, es importante, no solo la calidad y el tamaño de la tesela, sino también su estilo. El mosaico de A6 se asimilaría a "The Late Silhouette Style”, que se caracteriza por enfatizar las siluetas negras y separarlas del campo blanco, con líneas de contorno, y con divisiones anatómicas definidas por líneas interiores, datadas en el siglo I d. C. a partir de los años 30-40
(Clarke, 1979, pp. 62-63) ${ }^{10}$. Destacan las similitudes de estilo de este mosaico de tema marino con el del apodyterium $\mathrm{F}$ de mujeres de las Termas del Foro de Herculano (Cuarto Estilo pompeyano) (Guidobaldi, Grandi y Pisapia, 2014, pp. 347-348), cuyos delfines y tritón presentan el mismo tipo de aleta caudal y similar banda blanca que rodea al mosaico en sentido oblicuo. Asimismo, es muy semejante al mosaico $n^{\circ} 68$ de las termas junto a la Via dei Vigili en Ostia (Becatti, 1961, I, pp. 45-47; Clarke, 1979, pp. 62-63), datado en los años 40-50 d. C., coincidiendo las aletas dorsales y pectorales, y el diseño de la caudal (aunque con un número menor de apéndices). El uso de borde con banda de triángulos en el área itálica es frecuente, y no presenta límites temporales ni espaciales definidos, por lo que no puede usarse como indicador para la datación de mosaicos (Rinaldi, 2007, p. 31; Paolucci, 2012, pp. 53-54; Bueno, 2011, p. 205).

En conclusión, este mosaico presenta una figuración marina propia de ambientes termales, muy diferente a la de los mosaicos de la pars urbana (A24-2526-56-58), de los que se diferencia, además, por su preparación de mortero hidráulico y peor factura (128 teselas $/ 100 \mathrm{~cm}^{2}$ de A6 frente a 183-197 de los otros). Aunque es difícil establecer su cronología, la falta de policromía, su técnica y los paralelos, nos acercarían a un periodo de construcción situado en la segunda mitad del siglo I d. C.

En el tepidarium (A7) (Fig. 15) se han hallado restos de otro mosaico, algunos in situ y otros en niveles

10 Cfr. Palestra de Pompeya y Casa del Centenario de Pompeya (Clarke, 1979, pp. 62-63). Este estilo mezclado con "The Neronian fluid-high lights style" (Clarke, 1979, pp. 62-63) aparece en las Termas del Foro de Herculano y el pavimento del tepidarium $\mathrm{C}$ del sector masculino de las Termas del Foro (Herculano) de principios Cuarto Estilo (Guidobaldi, Grandi y Pisapia, 2014, pp. 343-344).
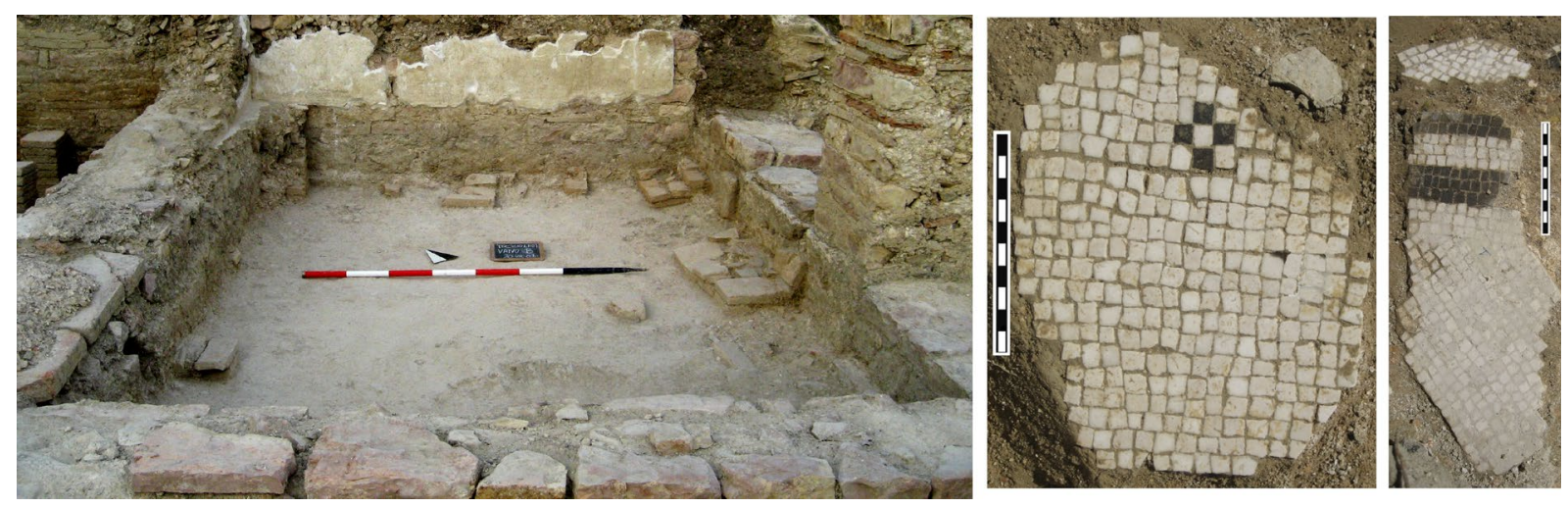

Figura 15. Mosaico de A7 (fotografía-imagen J. Molina Vidal y M. a J. López Medina). 


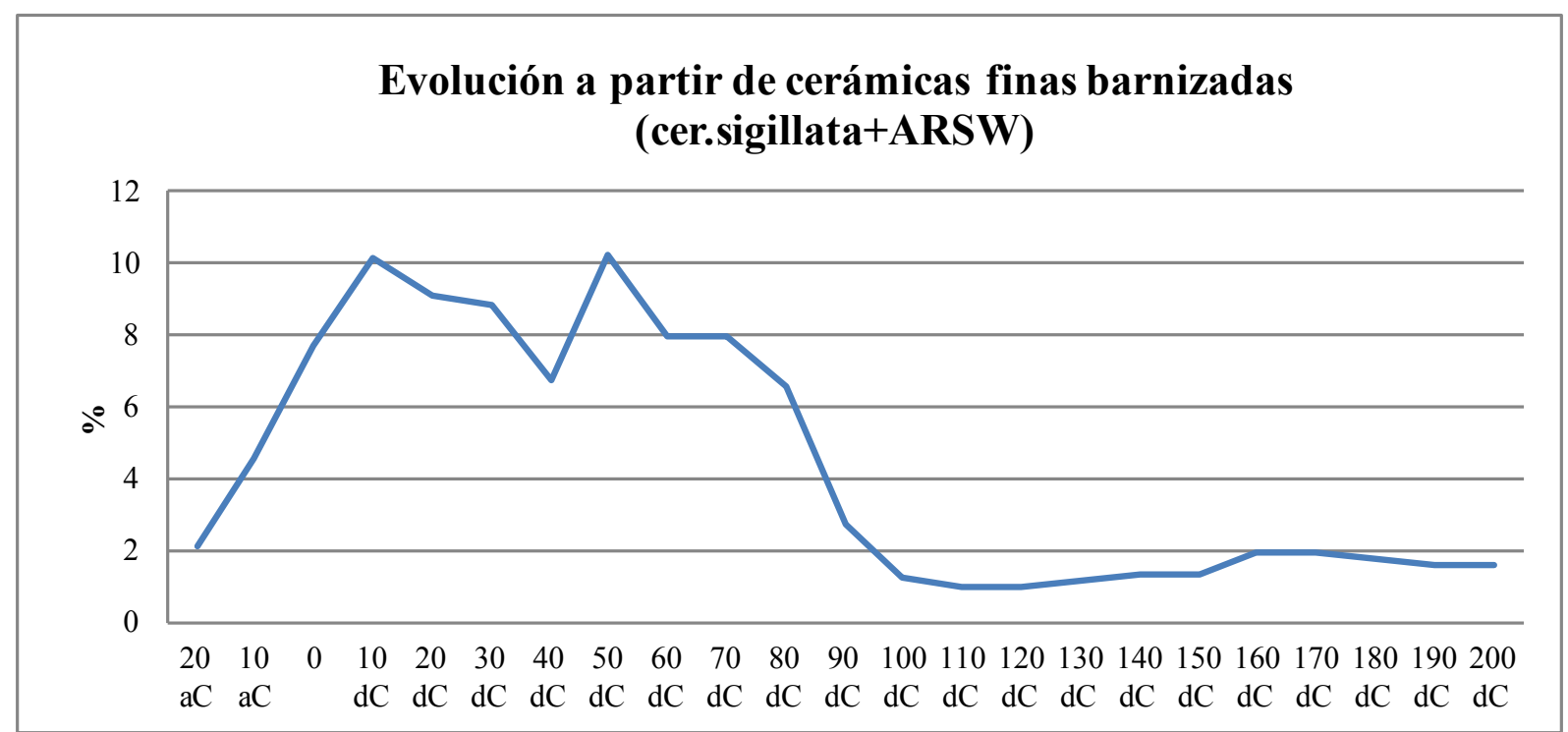

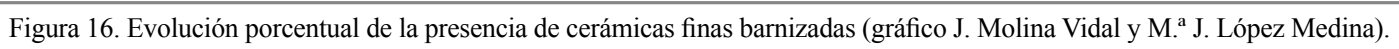

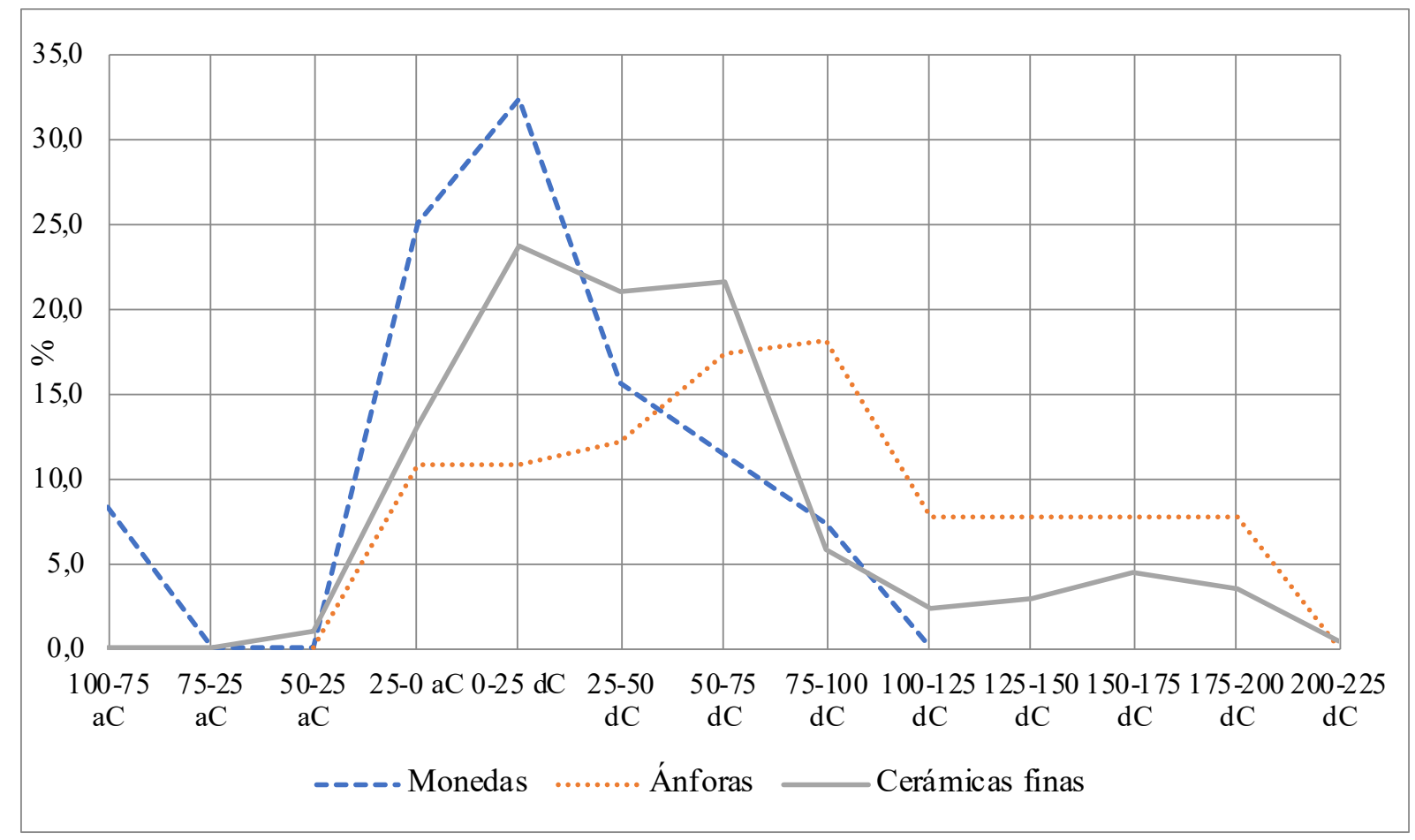

Figura 17. Evolución de la presencia monetaria (24 monedas), cerámica fina barnizada (177 bordes) y ánforas (71 bordes) (gráfico J. Molina Vidal y M. ${ }^{\text {J }}$. López Medina)

de derrumbe, cuyo módulo (c. 108 teselas/100 $\mathrm{cm}^{2}$ ) indica una calidad técnica inferior a los del Área 2, e incluso al del caldarium (A6). El campo presenta fondo blanco sembrado de cruces de cinco teselas bícromas en oposición de colores, es decir, cada cruz está formada por una tesela blanca rodeada de cuatro teselas negras, un motivo geométrico en blanco y ne- gro sobre fondo blanco en orden indirecto (Fig. 14) (Balmelle et al., 1985, pl. 108; motivo DM 108a, Rinaldi, 2007). Se trata de una composición atestiguada desde el periodo tardorrepublicano hasta el siglo II d. C. El borde que enmarca el campo está formado por dos bandas negras de tres filas de teselas, separadas por una banda blanca del mismo grosor, a su vez todo 
ello está encuadrado por sendas bandas blancas formadas también por tres filas de teselas, todo dispuesto en orden directo (Fig. 15). Por último, el mosaico estaba rodeado de una franja de teselas blancas dispuestas en sentido oblicuo al igual que ocurre en A6. Este borde es característico del Tercer Estilo y se mantiene durante el Cuarto, por ejemplo, se localiza en el mosaico del sacello A del Area Sacra de Herculano datado en el Tercer Estilo (Guidobaldi, Grandi y Pisapia, 2014, p. 27). Por tanto, como ocurre con A6, se trataría de un mosaico de la segunda mitad del siglo I d. C. sin entrar en el II d. C.

En conclusión, sería deseable tener mejor información estratigráfica pero el elevado nivel de destrucción y arrasamiento de las estructuras de esta fase de reestructuración (Fase 2) impide precisar más su cronología. Afortunadamente, los mosaicos que pavimentan el caldarium (A6) y el tepidarium (A7), de las nuevas y pequeñas termas que se construyen en la pars rustica amortizándola, nos ofrece una datación fiable (Figs. 13, 14 y 15): tercer cuarto del siglo I d. C., a lo sumo segunda mitad del siglo I d. C. La villa seguiría en actividad en esta Fase 2, como lo atestigua la producción local de ánforas Tipo Spello-AT1, de la que tenemos un descarte de horno, y las múltiples reformas constructivas descritas anteriormente. Sin embargo, desaparece el ergastulum, se reestructura la pars rustica y se amplía la pars fructuaria a costa de la pars urbana (Figs. 6 y 13). Esta parte señorial de la villa podría, incluso, haber perdido sus funciones residenciales dada la amortización del balneum de Fase 1. Todo parece indicar que la villa se convierte en un gran conjunto productivo y de almacenaje alejado de la villa esclavista y señorial que fue en la Fase 1.

\section{CRONOLOGÍA GENERAL Y EVOLUCIÓN DE LA VILLA}

La excavación de la villa de Rufio presenta unas características estratigráficas muy particulares pues los continuos trabajos agrícolas han arrasado en la gran mayoría de las áreas las estructuras, a excepción de las semienterradas del ergástulo o pars rustica (Molina et al., 2017). Además, los cimientos de las estructuras se asientan en niveles de tierra muy compactos en los que no se detectan fosas de fundación claras, o cuando se han encontrado no han ofrecido información cronológica.

Sin embargo, un análisis depurado de las cerámicas finas barnizadas (barniz negro, cerámica sigillata y ARSW), ánforas y monedas hallados en el yacimiento nos ha permitido realizar una aproximación estadística bastante precisa a la evolución cronoló- gica del conjunto (Figs. 16 y 17). Para empezar del análisis de las curvas de evolución se puede observar que, en términos generales, la frecuentación preferente del conjunto podría situarse entre el último tercio del siglo I a. C. y finales del siglo I d. C. o principios del II d. C. Las evidencias de ocupación anterior son muy débiles, pues las monedas (un cuadrante $R R C$ 339, 4d del 91 a. C. o un quinario $R R C 373,1$ b del 81 a. C.) pueden presentar períodos de circulación muy dilatados. Mientras que los escasísimos restos de barniz negro (especialmente tres bordes, dos de la forma Morel F2283/2284/2286 y uno de la Lamboglia 8a-Morel F2566) se asocian a las producciones más tardías 150-25 a. C., que podrían relacionarse con la fase inicial de la villa de la primera época augustea o poco anterior. Mucho más representativa es la ausencia total de las características ánforas tardorrepublicanas (Dressel 1 o Lamboglia 2), siendo las ánforas Dressel 2-4, Dressel 7-11 o Haltern 70, de época augustea y principios del siglo I d. C., los contenedores de transporte de cronología más temprana que se documentan (Fig. 17).

Para el final de la ocupación hemos de destacar la curiosa ausencia de monedas posteriores al siglo I d. C., excepción hecha de una única moneda ilegible adscribible a las emisiones de los siglos IV-V d. C. o algunas monedas del siglo XVII. Igualmente, evidente es la disminución de materiales anfóricos del siglo II d. C., siendo las ánforas Tipo Spello-AT1 contenedores que se empiezan a fabricar en la segunda mitad del siglo I d. C., las evidencias anfóricas más tardías aparecidas en la villa. La reducida presencia de ánforas africanas (tres bordes) nos prolonga al menos hasta la segunda mitad del siglo II d. C. algún tipo de frecuentación. De igual forma las cerámicas ARSW -claras africanas- escasas y aparecidas en unidades superficiales y de amortización, son todas del tipo A, tanto de la segunda mitad del siglo I d. C. y primera mitad del II d. C. (Hayes 3a, $\mathrm{H} 3 \mathrm{c}, \mathrm{H} 8 \mathrm{a}$ ), como de su segunda mitad (H6b, H7b, H8b, H9b, H14a, H27). Su presencia residual denota el considerable descenso de las importaciones y las actividades durante el siglo II d. C.

La evolución de los contenedores anfóricos (Fig. 17), que con el fin de aumentar la fiabilidad hemos circunscrito al recuento de bordes (72 fr.), marca una evolución semejante, aunque la fuerte presencia de ánforas Tipo Spello-AT1 (Molina, 2009), de las que se ha documentado la producción en la propia villa con la aparición de descartes de horno, eleva las proporciones en la segunda mitad del siglo I d. C. (Fig. 17). Las importaciones se vinculan básicamente a las salsas de salazón béticas (ánforas Dressel 7-11 y Dressel 14), aunque la mayoría de las ánfo- 
ras halladas son de producción local y vinculadas a los tipos Dressel 2-4 y Tipo Spello-AT1 (74,5\% del total de las ánforas). El análisis estadístico de las cerámicas finas barnizadas (Fig. 16) ofrece una mayor precisión y detalle sobre la evolución de su frecuentación: barniz negro -3 fr. de borde-, cerámicas sigillatas -150 fr. de borde- y ARSW -20 fr. de borde-). Como podemos observar en el gráfico proporcional (Fig. 16 y 17) se observan dos picos: uno en época augustea y otro a mediados del siglo I d. C., con una evidente caída a partir de finales del siglo. Una dinámica coincidente con el perfil ofrecido por los hallazgos monetarios que presenta un $75 \%$ del numerario, concentrado entre época augustea y flavia (Fig. 17).

Por su parte la información proporcionada por los mosaicos viene a redundar en el marco temporal propuesto, dada la total ausencia de teselas polícromas en todo el yacimiento. Los mosaicos de la Fase 1 (A24, A25, A26, A56 y A58) realizados en blanco y negro y que presentan elegantes motivos geométricos, buena calidad artística y linealidad, se datarían a finales del siglo I a. C., época augustea. A la de remodelación de la villa (Fase 2) se asocian los mosaicos del pequeño balneum del Área 1 (A6 y A7) de peor calidad técnica y motivos figurativos. La datación de estos mosaicos, y por tanto de la Fase 2, se situaría en la segunda mitad del siglo I d. C.

En conclusión, la secuencia de ocupación cronológica general del conjunto presentaría a grandes rasgos dos intensas fases constructivas (Fases 1 y 2) y una fase final de destrucción (Fase 3):

- Fase 1A. La fundación de la villa de Rufio: época augustea-último cuarto del siglo I a. C. Supondría la construcción del conjunto de la villa organizada en terrazas. Esta datación puede fundamentarse en la aparición de cerámicas sigillatas itálicas (informes) (último tercio siglo I a. C.-época de Augusto), ánforas Dressel 2-4 y cerámicas de paredes finas en los niveles fundacionales. Asimismo, cabe destacar la aparición de pavimentos de opus tessellatum en la pars urbana de datación augustea. Además, la inscripción anteriormente comentada y originalmente vinculada a la Fase 1 , presenta caracteres paleográficos coherentes con esta época (Llidó y Molina, 2012).

- Fase 1B: época tardoaugustea o tiberiana. Se reestructura el complejo termal o balneum ampliándolo y monumentalizándolo con la reforma de sus accesos, ampliación de los espacios, apertura de nuevos praefurnia y la construcción de un balneum calefactado y un frigidarium absidiado (A5).

- Fase 2: segunda mitad del siglo I d. C. Se observa una reestructuración completa de la villa consistente en la remodelación total de la pars rustica que se ve anulada y reducida a un solo piso, perdiendo muy pro- bablemente sus funciones como alojamiento servil. La clave la hallamos en la construcción de un pequeño balneum, formado por un caldarium (A6) y un tepidarium (A7), en ambos casos pavimentados con sendos mosaicos datables en la segunda mitad del siglo I d. C. Asimismo, se detectan remodelaciones del patio central del Área 1 (A9) que, como ocurre en el pequeño complejo termal (A6-7) se construye en opus mixtum, a diferencia de la obra de mampostería regular característica de la fase fundacional de la villa. Asimismo, en la pars urbana detectamos fuertes remodelaciones internas que suponen la ruptura de la simetría original de los espacios con la construcción de estancias y pavimentaciones de opus spicatum (A29) que parecerían indicar una ampliación de las áreas productivas en detrimento de las habitacionales.

- Fase 3: principios del siglo II d. C.-mediados del siglo II d. C. Finalmente detectamos una fase de destrucción y abandono de todo el conjunto. Es difícil ajustar la cronología de esta fase, pero los niveles de abandono de distintas unidades estratigráficas altamente fiables (UUEE 566, 550, 564, 527 entre otras) ofrecen dataciones con materiales predominantemente de la primera mitad del siglo II d. C., especialmente su primer tercio en lo que se refiere a las ánforas Africana piccolo (solo 4 fragmentos) y ánforas Tipo Spello-AT1 (1/2 siglo I d. C.-s. II d. C.). Las cerámicas ARSW-claras africanas, escasas apuntarían a niveles de frecuentación en las fases de abandono muy residuales lo largo de todo el II d. C. De hecho, como hemos señalado, no hemos hallado monedas del siglo II y solo una posible moneda de los ss. IV-V en niveles superficiales, frente a un $75 \%$ del numerario concentrado entre época augustea y flavia. Cabría destacar los signos de destrucción que observamos en todo el conjunto, documentados especialmente en niveles de relleno de los espacios aledaños al patio A9, repletos de restos constructivos (pavimentos, umbrales, fragmentos de pintura parietal y cornisas de estuco) que con toda probabilidad proceden de niveles destructivos, en algunos casos posiblemente de la pars urbana.

\section{CONCLUSIONES: LA VILLA DE RUFIO Y LOS LÍMITES DEL SISTEMA ESCLAVISTA EN ITALIA}

Gaius Iulius Rufio, personaje relacionado con el Rufio liberto de Julio César mencionado por Suetonio (De vita Caesarum 1.76), fundó en época augustea una villa esclavista (Fase 1) en el corazón de la Regio VI, junto a la vía Flaminia. Este rico propietario muy probablemente mantuvo sus relaciones con la familia imperial en época augustea, cuyo amparo le permitiría desarrollar una cómoda posición económica. De he- 
cho, este nombre lo encontramos solo en otra ocasión: en una inscripción hallada en uno de los columbarios de Vigna Codini, descubiertos en 1847 por P. Campana, de cuya original atribución a la familia Marcellae Minoris (CIL VI, 808-809) hay serias dudas (CIL VI, 4773). No obstante, la inscripción aparece junto a muchas otras de siervos y libertos imperiales, un conjunto epigráfico que se dataría en torno al $10 \mathrm{~d}$. C., elemento que sería coherente con otros indicios que apuntarían a una cronología tardoaugustea de este columbario (Llidó y Molina, 2012, p. 201).

La abundancia de ánforas Dressel 2-4 de procedencia local indicaría una producción mercantil, preferentemente de vino, en esta villa durante su primera fase que alcanzaría la mitad del siglo I d. C. Esta fase 1 en la que destaca su carácter esclavista se caracteriza por la existencia de un ergastulum de grandes dimensiones para albergar a los siervos de la villa. Durante este periodo tan solo se detecta una ampliación puntual del complejo termal (Fase 1B) que no supone una alteración sustancial de los espacios productivos o residenciales.

Sin embargo, en la segunda mitad del siglo I d. C. asistimos a una remodelación completa de la villa (Fase 2) con una ampliación de los espacios productivos y una disminución de los residenciales. En esta fase se amortiza el ergastulum de la villa, lo que apuntarían a un cambio de propiedad y producción importante que se proyectaría hacia nuevos tipos de mano de obra. La abundante presencia de ánforas Tipo Spello-AT1, con producción propia atestiguada, indicaría una continuidad de las producciones de vino. A finales del siglo I d. C. o principios del siglo II d. C. el conjunto es destruido, presumiblemente de manera súbita a tenor de los procesos de deposición repentinos de los niveles de relleno y destrucción. Toda esta secuencia constructiva y productiva nos sitúa ante el elemento central que justifica el título de este artículo: el desarrollo del modelo productivo de la villa y los límites de su carácter esclavista.

La esclavitud y el carácter esclavista de su sistema productivo es uno de los elementos centrales del debate sobre la economía romana. Habría que remontarse al Renacimiento para hallar las raíces de conceptos como sistema esclavista, villa esclavista o modo de producción esclavista que han constituido un verdadero paradigma de la economía romana, y que solo se ha puesto en cuestión por una parte minoritaria de la comunidad científica. Un reciente trabajo de B. Montoya Rubio (2011, 2016) sobre la evolución y fundamentos de la esclavitud antigua en la historiografía moderna ofrece un novedoso y revelador análisis que sitúa las raíces del paradigma esclavista de la economía romana en las propias fuentes antiguas, para ser construido sistemáticamente por la historiografía posterior, mucho más allá de figuras fundamentales como D.
Hume, A. Smith, T. Mommsen, E. Cicotti, M. Weber o M. Rostovtzeff o el propio M.I. Finley. En un ámbito más cercano en el tiempo cabría destacar el impulso renovado que la Escuela Gramsci (A. Carandini, A. Schiavone, M. Torelli o F. Coarelli, entre otros) dio al paradigma esclavista de la Antigüedad, partiendo de una relectura marxista muy dialéctica y de la incorporación de perspectivas historiográficas de la Escuela de los Annales, con figuras como F. Braudel. Frente a ellos la denominada Nueva Ortodoxia defendió visiones primitivistas (K. Polanyi) y, en algunos casos, incluso cuestionó abiertamente el carácter predominantemente esclavista de la economía romana, como hizo M. I. Finley $(1975,1982)$. En este contexto, la excavación de la villa de Settefinestre (Ager cosanus, Italia) (Carandini, 1985, 1988, 1989) supuso un refrendo material de las tradicionales interpretaciones esclavistas fundamentadas en argumentos filológicos, llevando hasta el siglo II d. C. la vigencia de los sistemas de producción serviles.

En el marco de este rico debate historiográfico sobre los límites y extensión del sistema esclavista romano es en el que podemos comprender la importancia de la datación augustea y julio-claudia de la fase esclavista de la villa de Rufio. No cabe duda de que los sistemas de producción esclavistas toman un papel preponderante en Italia durante la fase imperialista republicana (ss. II-I a. C.), el problema reside en fijar sus límites espaciales y temporales. Hay serias dudas acerca de su extensión masiva y de forma hegemónica en ámbitos provinciales, especialmente a partir de época augustea, pero la villa de Rufio nos muestra que en el corazón de Italia y en círculos cercanos al núcleo social imperial el sistema esclavista se abandonaría a mediados del siglo I d. C., a lo sumo al principio de época flavia.

La pax romana cerró una de las principales fuentes de abastecimiento de mano de obra servil: la guerra. De hecho, en la obra de Columela (1.8.19) o Apiano (BEL.CIV. 1.7) hallamos pruebas del fomento de la reproducción de esclavos, vislumbrando el final de un mundo en el que la abundancia de mano de obra servil garantizaba su bajo precio y disponibilidad. La convivencia de distintos tipos de mano de obra, libre y esclava, es una realidad en las fuentes escritas de la segunda mitad del siglo I d. C. y el II d. C., la villa de Rufio no hace más que ratificar esa evidencia.

La amortización de la pars rustica (ergastulum) y de la pars urbana a partir la segunda mitad del siglo I d. C. nos permite aportar una importante prueba sobre el límite máximo del desarrollo y auge de ese tipo de explotaciones. No estaríamos hablando de una desaparición súbita, sino de los límites máximos de expansión de un sistema que habría tocado techo y 
empezaría una transición hacía fórmulas mixtas de explotación, sistemas cuando menos diferentes. Se trata de unos límites que M. De Spagnolis (1982, pp. 353364) situó a finales del siglo I a. C.; E. Gabba (1982, pp. 371 y ss.) y M. Torelli (1982, p. 432) a mediados del siglo I d. C., y A. Carandini (1989, p. 194), partiendo de la villa de Settefinestre, llevó a finales del siglo I o principios del siglo II d. C.

En conclusión, el análisis de las fases constructivas de la villa de Rufio nos presenta una prueba material inequívoca, pues hablamos del abandono y transformación del ergastulum, del final de los sistemas de producción esclavistas de plantación en el centro de Italia a mediados del siglo I d. C. En el nuevo contexto económico policéntrico (Molina, 1997, 2020; Márquez y Molina, 2005) en el que las provincias han roto el tradicional marco de relaciones centro-periferia imperialistas, la transformación de la economía itálica sería imprescindible, sobre todo en un sistema tan complejo y dinámico como el romano.

\section{BIBLIOGRAFÍA}

Álvarez Tortosa, J. F. (2017). Modelos de producción en la agricultura comercial del noreste de la provincia Hispania Citerior. Alicante: Universidad de Alicante. Disponible en: http://hdl.handle.net/10045/82433 (consulta 2-12-2019).

Alvino, G. (1995). "Pavimenti musivi del territorio sabino". En: Bragantini, I. y Guidobaldi, F. (Eds.). Atti del II Colloquio dell'Associazione italiana per lo studio e la conservazione del mosaico. Bordighera: Istituto internazionale di studi liguri, pp. 501-516.

Balmelle, C., Blanchard-Lemée, M., Christophe, J., Darmon, J. P., Guimier, A. M., Sorbets- Lavagne, H., Prudhomme, R. y Stern, H. (1985). Le decor géometrique de la mosaique romaine. I. Repertoire graphique et descriptif des composicions linéaries et isotropes. Paris: Editions A\&J Picard.

Becatti, G. (Ed.) (1961). Scavi di Ostia. Vol. IV: Mosaici e pavimenti marmoreii. Roma: Istituto poligrafico dello Stato, Libreria dello Stato, 2 vols.

Blake, M. E. (1930). "The pavements of the Roman buildings of the Republic and Early Empire". Memoirs of the American Academy in Rome, 8, pp. 9-159.

Blanton, R. E. (1994). Houses and households: a comparative $s t u d y$. London \& New York (NY): Plenum Press.

Bueno, M. (2011). Mosaici e pavimenti della Toscana (II secolo a.C.- V secolo d.C.). Antenor Quaderni, 22. Roma: Quasar.

Bueno, M., Novello, M. y Rinaldi, F. (2012). "Per un corpus dei mosaici di Aquileia: status quo e prospettive future". En: Bonetto, J. y Salvadori, M. (Eds.). L'architettura privata ad Aquileia in età romana. Atti del convegno di studio (Padova, 21-22 Febbraio 2011). Antenor Quaderni, 24. Padova: Padova University Press, pp. 195-220.

Carandini, A. (1985). Settefinestre una villa schiavistica nell'Etruria romana. Modena: Panini.
Carandini, A. (1988). Schiavi in Italia. Gli strumenti pensanti dei tarda Repubblica e medio Imperio. Roma: La Nuova Italia Scientifica.

Carandini, A. (1989). "La villa romana e la piantagione schiavistica”, Storia di Roma, IV. Caratteri e morfologie. Torino: Einaudi, pp. 101-200.

Clarke, J. R. (1979). Roman Black-and-White Figural Mosaics. New York: College Art Association of America.

De Franceschini, M. (2005). De Ville dell'Agro romano. Roma: L'Erma Di Bretschneider.

De Simone, A. y Ruffo, F. (2005). "I mosaici della Villa dei Papiri ad Ercolano (NA). Il quartiere dell'atrio". En: Angelelli, C. (a cura di) Atti del X Colloquio dell'Associazione Italiana per lo Studio e la Conservazione del Mosai$c o$, con il patrocinio del Ministero per i Beni e le attività Culturali (Lecce, 18-21 febbraio 2004). Tivoli: Scripta Manent edizioni, pp. 161-182.

De Spagnolis, M. (1982). "Ville rustiche e trasformazione agraria nel Lazio meridionale". Lefevre, R. (Ed.). Il Lazio nell'Antichità romana. Roma: F.lli Palombi, pp. 353-364.

Dunbabin, K. M. D. (1999). Mosaics of the Greek and Roman World. Cambridge: Cambridge University Press.

Finley, M. I. (1975). La economía de la Antigüedad. México: Fondo de Cultura Económica.

Finley, M. I. (1982 [1980]). Esclavitud antigua e ideología moderna. Barcelona: Crítica.

Gabba, E. (1982). "Per la storia della societá romana tardorepubblicana". Opus, 1 (2), pp. 373-387.

Grau Mira, I. y Molina Vidal, J. (2010). "La Villa de Rufio (Giano dell'Umbria, Italia): la delimitación del área residencial (Campaña 2010)". En: Excavaciones en el exterior 2009. Informes y trabajos, 5. Madrid: Secretaría General Técnica Subdirección General de Publicaciones, Información y Documentación, pp. 178-187. https:// www.libreria.culturaydeporte.gob.es/libro/informes-ytrabajos-5-excavaciones-en-el-exterior-2009_1374/

Guidobaldi, F., Grandi, M. y Pisapia, M. S. (2014). Mosaici Antichi in Italia, Regione Prima, Ercolano. Pisa-Roma: Fabrizio Serra Editore

Hillier, B. y Hanson, J. (1984). The Social Logic of Space. Cambridge: Cambridge University Press.

Llidó López, F. y Molina Vidal, J. (2012). “Caius Iulius Rufio propietario en la vía Flaminia, entre Suetonio y la epigrafía". Epigraphica. Periodico Internazionale di Epigrafia, LXXIV (1-2), pp. 75-82.

Lugari, A. y Grandi, M. (2004). "Riflessioni sui rapporti tra scelte iconografiche e tecniche esecutive nel mosaico romano (I sec. a.C.- I sec. d.C.) (Relazione preliminare)". Atti del IX Colloquio dell'Associazione italiana per lo studio e la conservazione del mosaico: Aosta, 20-22 febbraio 2003. Ravenna: Edizioni del Girasole, pp. 441-454.

Márquez Villora, J. C. y Molina Vidal, J. (2005). Del Hiberus a Carthago Noua. Comercio de alimentos y epigrafia anfórica grecolatina. Instrumenta, 18. Barcelona: Universitat de Barcelona, Publicacions i Edicions de la Universitat de Barcelona.

Molina Vidal, J. (1997). La dinámica comercial romana entre Italia e Hispania Citerior. Alicante: Publicaciones de la Universidad de Alicante. 
Molina Vidal, J. (2009). "Mercantile Trade in the Upper Tiber Valley: the Villa of Pliny the Younger 'in Tuscis"'. En: Coarelli, F. y Patterson, H. (Eds.). Mercator Placidissimus. The Tiber Valley in Antiquity. New research in the upper and middle river valley. Atti del Convegno, Roma, British School at Rome, 27-28 febbraio 2004. Quaderni di Eutopia, 8. Roma: Quasar, pp. 215-249.

Molina Vidal, J. (2020). El sistema policéntrico romano. Sant Vicent del Raspeig: Publicacions de la Universitat d'Alacant.

Molina Vidal, J., Grau Mira, I., Llidó López, F. y Álvarez Tortosa, J. F. (2017). "Housing slaves on Roman estates: a proposed ergastulum at the Villa of Rufio (Giano dell'Umbria)". Journal of Roman Archaeology, 30, pp. 387-406.

Montoya Rubio, B. (2011). L'esclavitud en l'economia antiga: evolució i fonaments de la historiografia moderna. Alicante: Universidad de Alicante. Disponible en http://hdl.handle.net/10045/23656

Montoya Rubio, B. (2016). L'esclavitud en l'economia antiga. Fonaments discursius de la historiografia moderna (segles $X V$-XVIII). Besançon: Presses universitaires de Franche-Comté .

Moretti, M. y Sgubini Moretti, A. M. (1977). La villa dei Volusii a Lucus Feroniae. Roma: Autostrade S.P.A.

Morricone Matini, M. L. (1967). Mosaici antichi in Italia, Regione Prima. Roma: Reg. X Palatinum. Roma: Ist. Poligrafico dello Stato - Libreria dello Stato.

Paolucci, G. (2012). Mosaici e pavimenti dell'Emilia Romagna (Regio VIII). Padova: Ph.D. thesis, Università degli studi di Padova. Dipartimento di archeologia. http://paduaresearch.cab.unipd.it/4519/1/Tesi_per_ internet.pdf
Pisapia, M. S. (2004). "Il complesso musivo pavimentale dell'ala occidentale del Museo Archeologico Nazionale di Napoli: un mosaico di mosaico". Apparati musivi antichi nell'area del Mediterraneo: conservazione programmata e recupero, contributi analitici alla Carta del rischio : atti del I Convegno internazionale di studi La materia e i segni della storia: Piazza Armerina, 9-13 aprile 2003. Palermo: Centro regionale per la progettazione e il restauro, pp. 60-70.

PPM = Baldassarre, I. (Coord.) (1990-2003). Pompei. Pitture e Mosaici, vol. I (Regio I. parte 19) 1990; vol. II (Regio I, parte 29) 1990; vol. III (Regiones II, III, V) 1991; Vol. IV (Regio VI, parte 19) 1993; vol. V (Regio VI, parte $2^{9}$ ) 1994; vol. VII (Regio VII, parte 29) 1997; vol. VIII (Regiones VIII e IX, parte $1^{9}$ ) 1998. Roma: Istituto della Enciclopedia italiana.

Rapoport, A. (1978). Aspectos humanos de la forma urbana. Barcelona: Gustavo Gili .

Rinaldi, F. (2007). Mosaici e pavimenti del Veneto. Province di Padova, Rovigo, Verona e Vicenza (I sec. a.C.-VI sec. d. C.). Antenor Quaderni, 7. Venezia: Quasar.

Torelli, M. (1982). "Intervención en la discusión de "Societá romana e produzione schiavistica". Opus, 1(1), p. 432.

Werner, K. (2006). "The Mosaics". En: Frischer, B., Crawford, J. y De Simone, M. (Eds.). The Horace's Villa Project 1997-2003. Oxford, England: Archaeopress. Vol. I, pp. 253-266; vol. II, pp. 853-871. http://hdl.handle.net/2027/heb.90044.0001.001 